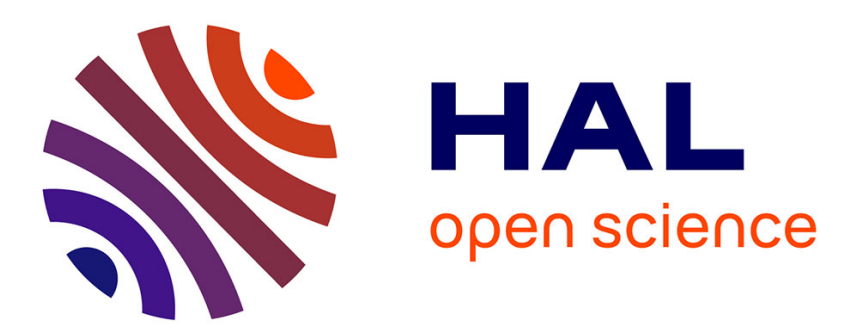

\title{
A 1D nonlinear finite element model for analysis of composite foam-insulated concrete sandwich panels
}

M. Lezgy-Nazargah, Philippe Vidal, Olivier Polit

\section{To cite this version:}

M. Lezgy-Nazargah, Philippe Vidal, Olivier Polit. A 1D nonlinear finite element model for analysis of composite foam-insulated concrete sandwich panels. Composite Structures, 2019, 210, pp.663-675. hal-01984028

\section{HAL Id: hal-01984028 \\ https://hal.parisnanterre.fr/hal-01984028}

Submitted on 16 Jan 2019

HAL is a multi-disciplinary open access archive for the deposit and dissemination of scientific research documents, whether they are published or not. The documents may come from teaching and research institutions in France or abroad, or from public or private research centers.
L'archive ouverte pluridisciplinaire $\mathbf{H A L}$, est destinée au dépôt et à la diffusion de documents scientifiques de niveau recherche, publiés ou non, émanant des établissements d'enseignement et de recherche français ou étrangers, des laboratoires publics ou privés. 


\title{
A 1D nonlinear finite element model for analysis of composite foam- insulated concrete sandwich panels
}

\author{
M. Lezgy-Nazargah, P. Vidal, O. Polit
}

\section{Introduction}

Due to specific properties such as high thermo-acoustic efficiency, high blast resistance, high workability and low self-weight characteristics, foam-insulated concrete sandwich panels are nowadays applied extensively in constructions of various civil engineering structures. As shown in Fig. 1, the FICSP structures are made of insolation foam, concrete, shear connectors, longitudinal rebar and welded wire reinforcements (WWR). The connectivity between the upper and lower concrete layers, which are referred as wythes, is provided using shear connectors. Different materials like polystyrene, fiberglass and rock wool are used for insulation layer. The expanded polystyrene (EPS) and extruded expanded polystyrene (XEPS) are the most common materials which are used for the insolation foams [1]. Dayton superior delta tie, Thermomass rod, standard steel C-clip and universal Teplo tie are some of various types of shear connectors [2]. Without shear connectors, there is no connection between concrete wythes and insulation layer. In this case, the FICSP has non-composite action and slip occurs at the interfaces between concrete wythes and insulation layer when it is bent. When a FICSP has sufficient number of shear connectors, its constituent layers will act together as a single unit to resist bending. In this case, it will have a fully composite action and no slip occurs at the interface between concrete wythes and insulation layer. It has been observed that generally the composite action of FICSPs is somewhere between the fully composite action and the non-composite action, and is called the partial composite action.

The mechanical behavior of FICSP structures is to some extent similar to traditional sandwich structures which are fabricated by fastening two thin but stiff face-sheets to a thick but lightweight core. In both of them, there is a large difference between the mechanical properties of core and upper/lower face-sheets. Different laminated theories are presented until now for the analysis of traditional sandwich structures. A finite element based on the variables separation method was presented by Vidal et al. [3] for the thermo-mechanical analysis of sandwich beams. Vidal and Polit [4] proposed a 6-node triangular finite element for analysis of multilayered composite and sandwich plates subjected to mechanical and thermomechanical loads. The formulation of this reference is based on the sinus model with layer refinement and it includes the transverse normal effects. An efficient finite element method based on global-local theory was introduced by Lezgy-Nazargah and colleagues [5-7] for bending and vibration analyses of laminated composite and sandwich beams. A large variety of plate theories including classical, higher order, zigzag, layerwise, and mixed theories were described and assessed by Carrera and Brischetto [8] to evaluate the bending and vibration of sandwich structures. By adding a zig-zag function to displacement fields of known theories, Brischetto et al. [9] developed higher order theories for bending analysis of sandwich flat panels. A very flexible variable kinematics modeling 


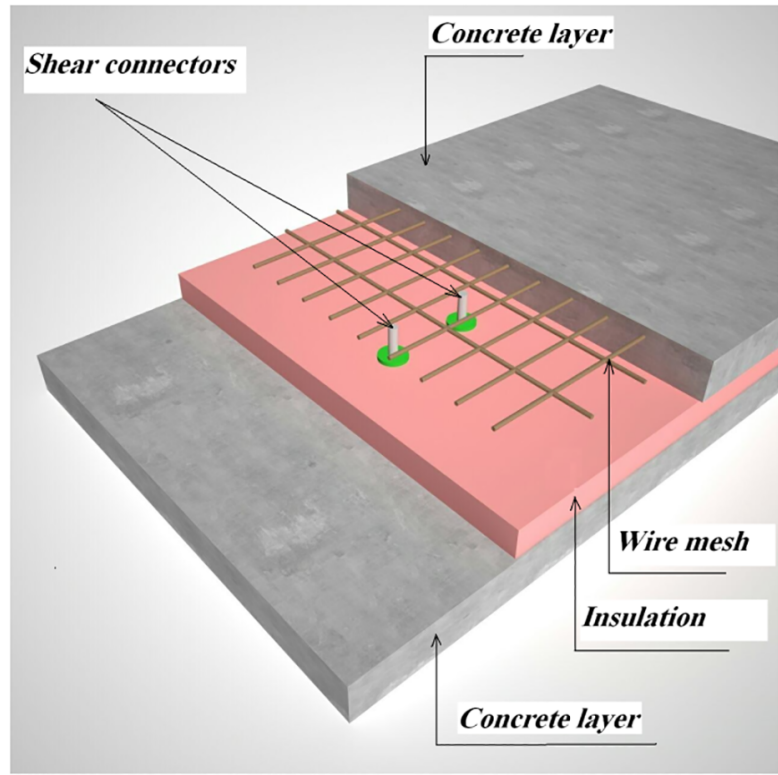

Fig. 1. Main constituent elements of the typical FISCP structures.

technique based on sublaminate Generalized Unified Formulation was proposed by D'Ottavio [10] for the analysis of laminated composite and sandwich structures. Choe et al. [11] investigated the post-buckling behavior of sandwich structures. They used a novel one-dimensional layer-wise model using Euler-Bernoulli beam theory in the skins and higher-order kinematics in the core. Shen et al. [12] studied bending deflections of soft-core sandwich beams subject to concentrated loads. Two correction factors to the classical deflection formula were proposed by them based on the higher-order theory approach. By expanding the displacement field into Fourier series, Huang et al. [13] studied the instability phenomena of sandwich plates. Saoud and Grognec [14] introduced an advantageous 1D finite element model to analyze the post-buckling behavior of sandwich beams. They modeled the thin skin layers as Timoshenko-Reissner beams. In this reference, the complex behavior of core layer is represented by specific kinematics involving hyperbolic functions. The buckling behavior of two-layer shear-deformable beams with partial interaction was studied by Grognec et al. [15]. They considered Timoshenko kinematic hypotheses for both layers. For representing the shear connection, they assumed a continuous relationship between the interface shear flow and the corresponding slip. Challamel et al. [16] studied the out-of-plane vibrations of composite and sandwich beams with interlayer slip for general boundary conditions by exact and finite element methods. For more details about various theories and numerical models on sandwich beams structures, the interested readers can refer to [17-20]. However, most of these available laminate theories are not appropriate for the structural analysis of FICSP systems. In contrast to traditional sandwich structures which are made from metallic face sheets, FICSPs consist of concrete wythes. Failure mode in traditional sandwich structures is local buckling of face-sheets while the concrete cracking/crushing is the dominant failure modes in FICSPs. Traditional sandwich structures have a relatively high composite action and can be considered in some extent as a "fully composite" structure. In FICSP structures, stiffness and spacing of shear tie connectors will cause partial composite action to occur between the foam and concrete layers.

Benayoune et al. [21] studied the structural behavior of FICSPs made of steel truss shear connectors experimentally. Six full-scale FICSP with variable slenderness ratio were tested under eccentric loads till failure. Woltman et al. [22] investigated the behavior of FICSP made of Glass fiber-reinforced polymer shear connectors via experimental tests. Naito et al. [2] studied experimentally the blast resistance of FICSP structures. Flexural behavior of FICSPs with FRP shear connectors was studied numerically and experimentally by Chen et al. [23]. Carbonari et al. [24] studied experimentally the flexural behavior of FICSPs containing inclined shear connectors under different boundary conditions. Using 2D finite element model and considering both geometrical and material nonlinearities, Benayoune et al. [25] studied the axial strength capacity of FICSP structures. They also carried out full scale tests in order to validate their finite element model. Bai and Davidson [26] introduced an analytical solution for the analysis of simply supported FICSP structures in elastic regime. They considered the effects of both partial composite action and shear deformation of insulation layer in formulations. With considering the nonlinear behavior of foam, concrete and rebar, Kang [27] used a 3D nonlinear finite element model (ABAQUS) for simulating the structural behavior of FICSPs. In [27], the multi-point constraints method is used for modeling the shear connectors.

The review of open literature shows that most of research works on FISCP structures are experimental studies. The 2D and 3D finite element models introduced for the structural analysis of FISCPs are computationally expensive methods and cannot be used for the practical design purposes. To fill this gap, a new displacement-based materially nonlinear 1D finite element model with low number of degrees of freedom (DOFs) is introduced for the flexural analysis of FISCP structures. Thanks to introducing a Sine function in the assumed displacement fields, the presented finite element model takes into account the transverse shear deformations induced in concrete wythe and middle insolation layers. The partial composite action of FISCP has been modeled based on spring layer model concept. Shear correction factor is not needed in the presented nonlinear formulation and the zero conditions of the transverse shear stress on the external plane of concrete wythes are fulfilled exactly. Max stress failure criterion is used for the detection of failure in insulation layer. Elasto-plastic model is used for modeling the material nonlinearity of steel rebar. The material acting manner of concrete after tensile crack is modeled via smeared crack method while the elasto-plastic model is employed for capturing the compressive behavior of concrete. A standard 1D displacement-based nonlinear finite element model is derived for solving the governing differential equations. The developed element has three nodes and 22 DOFs. The full-scale experimental data, the 3D finite element results and other analytical approaches have been used to validate the present formulation.

\section{Coordinate system and kinematic}

As shown in Fig. 2a, the considered FISCP structure is made of three main constituent elements: top concrete wythe, insulation layer and bottom concrete wythe. In this figure, the chosen coordinate systems for constituent elements are also shown. The coordinate systems are taken so that the coordinate plane $y$ - $z$ lies on the cross-section symmetry plane of the FISCP structure. Each constituent element of FISCP is divided into a series of sub-layers. Although the material property and strain at each constituent element are independent on the number of sub-layers, the sub-layer discretization is required for the purpose of materially nonlinear analysis. As shown in Fig. 2b, longitudinal steel rebar embedded in top and bottom concrete wythes are treated as being steel layers with equivalent thickness $t_{s}=A_{s} / b$ (where $A_{s}$ is the total cross-section area of steel rebar in each wythe). These equivalent steel layers are placed at the centerline of the longitudinal steel rebar.

The following expressions are defined for representing the axial $\left(U_{i}\right)$ and transverse displacement $\left(W_{i}\right)$ in insolation layer and two concrete wythes:

$U_{i}^{(k)}\left(x, y, z_{i}\right)=u_{0 i}(x)-z_{i} \frac{\partial w(x)}{\partial x}+\left(\frac{h_{i}}{\pi}\right) \sin \left(\frac{\pi z_{i}}{h_{i}}\right)\left(\omega_{i}(x)+\frac{\partial w(x)}{\partial x}\right)$ 


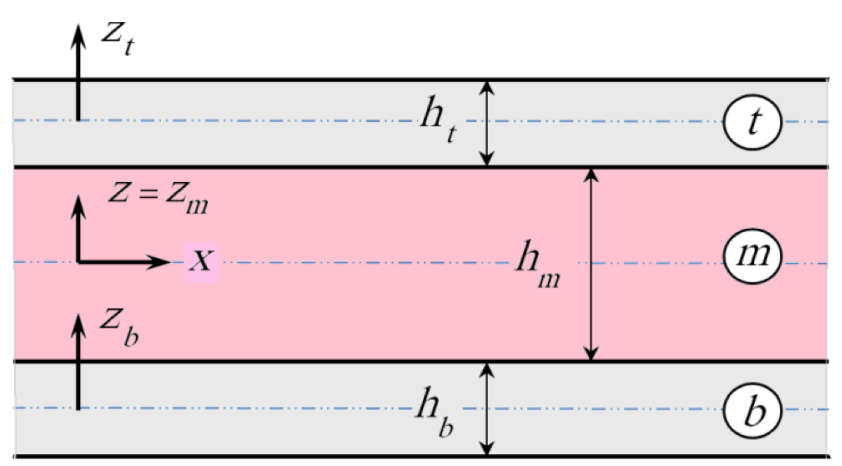

(a)

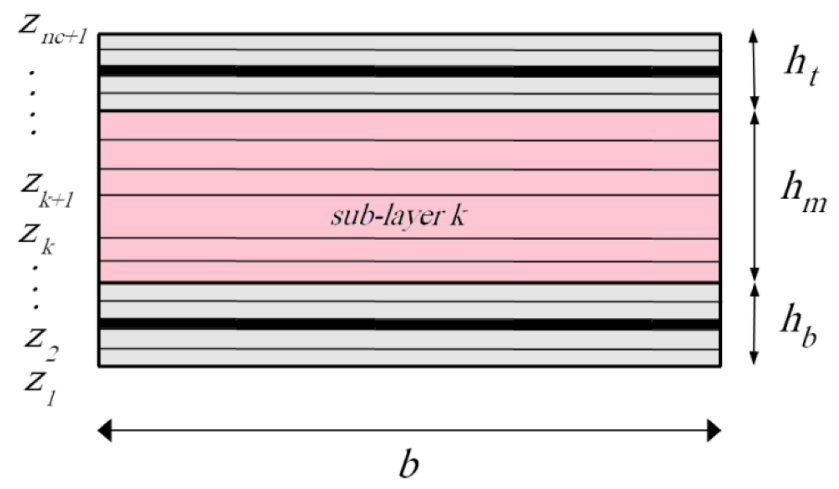

(b)

Fig. 2. Coordinate system and typical geometry of FICSPs: (a) side view, (b) cross-section.

$W_{i}^{(k)}\left(x, y, z_{i}\right)=w(x)$

where subscript $i=t, m, b$ denote the top concrete wythe, insolation layer and bottom concrete wythe, respectively. Superscript $k$ represents the sub-layer number. $u_{0 i}$ is the axial displacement at mid-plane of each constituent element. $h_{i}$ denotes the total thickness of insulation/wythe layers. The shear-bending rotation of constituent elements around the $y$ axis is represented with $\omega_{i}(x) . w$ denotes the transverse displacement of FICSPs whose variations are assumed to be constant along the thickness direction of FICSP system. From Eq. (1), it is seen that the assumed kinematic has only seven global unknown variables: $u_{0 b}, w, \omega_{b}, u_{0 m}, \omega_{m}$, $u_{0 t}, \omega_{t}$.

Using the well-known strain-displacement relations, axial and shear strains at the $k$ th sub-layer of FICSP can be determined from the following relations:

$$
\begin{aligned}
\left(\varepsilon_{x x}^{(k)}\right)_{i}\left(x, y, z_{i}\right)= & \frac{\partial u_{0 i}(x)}{\partial x}-z_{i} \frac{\partial^{2} w(x)}{\partial x^{2}} \\
& +\left(\frac{h_{i}}{\pi}\right) \sin \left(\frac{\pi z_{i}}{h_{i}}\right)\left(\frac{\partial \omega_{i}(x)}{\partial x}+\frac{\partial^{2} w(x)}{\partial x^{2}}\right) \\
\left(\gamma_{x z}^{(k)}\right)_{i}\left(x, y, z_{i}\right)= & \cos \left(\frac{\pi z_{i}}{h_{i}}\right)\left(\omega_{i}(x)+\frac{\partial w(x)}{\partial x}\right)
\end{aligned}
$$

It is easy to find from Eq. (2) that the transverse shear stress $\gamma_{x z}$ becomes zero at $z_{t}=h_{t} / 2$ and $z_{b}=-h_{b} / 2$. Thus, the considered kinematic does not need the shear correction factor. The geometrically nonlinear effects are not considered in the present formulation since FICSP structures are not generally designed to operate in this regime.

Due to the partial composite action of shear ties, relative sliding will appear at the interface between the insolation layer and concrete wythes. This phenomenon has been modeled using distributed elastic shear springs which are placed at the interfaces between insulation layer and concrete wythes. The stiffness of these distributed springs may be approximated based on the real tangential stiffness of shear ties and distance between them. The slip at the interface between insulation layer and top concrete wythe can be determined as follow:

$$
\begin{aligned}
s_{t m}= & U_{t}\left(x, z_{t}=-h_{t} / 2\right)-U_{m}\left(x, z_{m}=h_{m} / 2\right)=u_{0 t}(x)-u_{0 m}(x) \\
& +\left(h_{m} / 2+h_{t} / 2-h_{t} / \pi-h_{m} / \pi\right) \frac{\partial w(x)}{\partial x}-\left(h_{t} / \pi\right) \omega_{t}(x)-\left(h_{m} / \pi\right) \omega_{m}
\end{aligned}
$$

Similarly, the relative sliding at the interface between the bottom concrete wythe and insulation layer can be approximated as:

$$
\begin{aligned}
s_{m b}= & U_{m}\left(x, z_{m}=-h_{m} / 2\right)-U_{b}\left(x, z_{b}=h_{b} / 2\right)=u_{0 m}(x)-u_{0 b}(x) \\
& +\left(h_{b} / 2+h_{m} / 2-h_{m} / \pi-h_{b} / \pi\right) \frac{\partial w(x)}{\partial x}-\left(h_{m} / \pi\right) \omega_{m}(x) \\
& -\left(h_{b} / \pi\right) \omega_{b}
\end{aligned}
$$

\section{Constitutive relations}

\subsection{Insulation layer}

Before the occurrence of failure, the following linear elastic behavior is assumed for the $k$ th sub-layer of insulation layer:

$\left\{\begin{array}{l}\sigma_{x x}^{(k)} \\ \sigma_{x z}^{(k)}\end{array}\right\}=\left[\begin{array}{cc}E_{x x}^{m} & 0 \\ 0 & G_{x z}^{m}\end{array}\right]\left\{\begin{array}{l}\varepsilon_{x x}^{(k)} \\ \gamma_{x z}^{(k)}\end{array}\right\}$

or

$\sigma_{m}^{(k)}=\boldsymbol{D}_{m}^{(k)} \boldsymbol{\varepsilon}_{m}^{(k)}$

where $G_{x z}^{m}$ and $E_{x x}^{m}$ are shear and Young's modulus of insulation layer, respectively. The Maximum stress criterion is used for detecting the occurrence of failure in the insulation layer. Based on this criterion, the failure occurs at a point in the insulation layer when the stress components satisfy one of the below conditions [28]:

$\sigma_{x x} \geqslant X_{t} \quad\left(\sigma_{x x}>0\right)$

$\sigma_{x x} \leqslant-X_{c} \quad\left(\sigma_{x x}<0\right)$

$\left|\sigma_{x z}\right| \geqslant S_{x z}$

where $X_{c}, X_{t}$ and $S_{x z}$ denote uniaxial compressive strength, uniaxial tensile strength and shear strength in $x-z$ plane, respectively. After failure, the elastic constants of insulation layer degrade to zero [28].

\subsection{Steel rebar}

It is assumed that no slip occurs at the interface between steel rebar and concrete wythes. The constitutive relations for the $k$ th equivalent steel layer can be expressed as follow:

$\left\{\begin{array}{c}\sigma_{x x}^{(k)} \\ \sigma_{x z}^{(k)}\end{array}\right\}=\left[\begin{array}{cc}E_{s} & 0 \\ 0 & \frac{E_{s}}{2\left(1+v_{s}\right)}\end{array}\right]\left\{\begin{array}{c}\varepsilon_{x x}^{(k)} \\ \gamma_{x z}^{(k)}\end{array}\right\}$

$\nu_{s}$ and $E_{s}$ are Poisson's ratio and Young's modulus of the steel layers, respectively. The above relation can be written as the following matrix form:

$\sigma_{s}^{(k)}=\boldsymbol{D}_{s}^{(k)} \boldsymbol{\varepsilon}_{s}^{(k)}$

Elasto-plastic model is considered for the material behavior of steel layers after yielding. In this condition, the incremental constitutive equations revert to

$d \sigma_{s}^{(k)}={ }^{t} \boldsymbol{D}_{s}^{(k)} d \varepsilon_{s}^{(k)}$

where 
${ }^{t} \boldsymbol{D}_{s}^{(k)}=\boldsymbol{D}_{s}^{(k)}-\frac{\boldsymbol{D}_{s}^{(k)}\left\{\frac{\partial f\left(\sigma_{s}^{(k)}\right)}{\partial \sigma_{s}^{(k)}}\right\}\left\{\frac{\partial f\left(\sigma_{s}^{(k)}\right)}{\partial \sigma_{s}^{(k)}}\right\}^{T} \boldsymbol{D}_{s}^{(k)}}{\left\{\frac{\partial\left(\sigma_{s}^{(k)}\right)}{\partial \sigma_{s}^{(k)}}\right\}^{T} \boldsymbol{D}_{s}^{(k)}\left\{\frac{\partial\left(\sigma_{s}^{(k)}\right)}{\partial \sigma_{s}^{(k)}}\right\}}$

and $f(\sigma)$ is the von Mises yield function. The expression of $f(\sigma)$ is given in Appendix A.

\subsection{Concrete wythes}

Before cracking/crushing, the following linear elastic behavior is assumed for the $k$ th concrete layer:

$\left\{\begin{array}{c}\sigma_{x x}^{(k)} \\ \sigma_{x z}^{(k)}\end{array}\right\}=\left[\begin{array}{cc}E_{c} & 0 \\ 0 & \frac{E_{c}}{2\left(1+v_{c}\right)}\end{array}\right]\left\{\begin{array}{l}\varepsilon_{x x}^{(k)} \\ \gamma_{x z}^{(k)}\end{array}\right\}$

or

$\sigma_{c}^{(k)}=\boldsymbol{D}_{c}^{(k)} \boldsymbol{\varepsilon}_{c}^{(k)}$

where $v_{c}$ and $E_{c}$ denote Poisson's ratio and Young's modulus of concrete. In this study, smeared crack modeling is adopted for representing the behavior of concrete after tensile cracking. According to this constitutive model, the incremental stress-strain relations at a point after concrete cracking revert to:

$\left\{\begin{array}{l}d \sigma_{11}^{(k)} \\ d \sigma_{13}^{(k)}\end{array}\right\}=\left[\begin{array}{cc}0 & 0 \\ 0 & \beta \frac{E_{c}}{2\left(1+v_{c}\right)}\end{array}\right]\left\{\begin{array}{l}d \varepsilon_{11}^{(k)} \\ d \gamma_{13}^{(k)}\end{array}\right\}$

or

$d \sigma_{c}^{(k)}={ }^{t} \boldsymbol{D}_{c}^{(k)} d \varepsilon_{c}^{(k)}$

where $\beta$ denotes the shear retention factor whose range is between 0 and 1 . The subscripts 1 and 3 are direction perpendicular and parallel to the tensile crack, respectively. In this study, the constant value $\beta=0.001$ is assumed for the shear retention factor. Interested readers can refer to [29] for more details about the proper selection of shear retention factor.

Concerning the material behavior of concrete after compressive crushing, elasto-plastic model is employed.

\section{Finite element formulation}

The standard finite element method is used for solving the governing differential equations of the FICSPs. By adopting suitable interpolation schemes for the unknown displacement field variables, the finite element formulation is derived from the following virtual work principle:

$$
\begin{gathered}
\sum \int_{l_{e}} \delta \varepsilon_{i}^{T} \sigma_{i} A_{i} d x+\sum \int_{l_{e}} b \delta s_{t m} \bar{k} s_{t m} d x+\sum \int_{l_{e}} b \delta s_{m b} \bar{k} s_{m b} d x \\
\quad-\sum \int_{l_{e}} \delta \boldsymbol{u}_{i}^{T} \overline{\boldsymbol{P}}_{i} d x-\sum \int_{V_{e}} \delta \boldsymbol{u}_{i}^{T} \overline{\boldsymbol{P}}_{i}^{V} d V=0
\end{gathered}
$$

$\mathrm{A}_{\mathrm{i}}, \overline{\boldsymbol{P}}_{i}$ and $\overline{\boldsymbol{P}}_{i}^{V}$ denote the cross-section area, surface and body force vectors, respectively. $i=t, m, b$ and $\bar{k}$ is the equivalent stiffness of the shear ties. $l_{e}$ and $V_{e}$ denote the length and volume of elements, respectively. $e$ is the total number of elements.

Since the unknown field variables of the FICPS are only function of $x$ coordinate, a 1D finite element formulation is adopted. The variations of transverse displacement $w(x)$ within each element are approximated using Hermite shape functions. Other displacement field variables are approximated using quadratic Lagrangian shape functions. Thus, one can write the vector of displacement variables with respect to the nodal displacement vector as below:

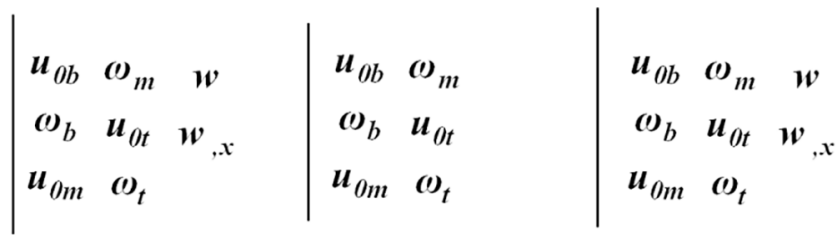

Fig. 3. The three-node FICSP element and related degrees of freedom.

$\boldsymbol{u}=\boldsymbol{N} \hat{\boldsymbol{u}}^{e}$

where $\quad \boldsymbol{u}^{T}=\left\{\begin{array}{llllllll}u_{0 b} & w & \omega_{b} & u_{0 m} & \omega_{m} & u_{0 t} & \omega_{t}\end{array}\right\}, \quad \boldsymbol{N}=\left[\begin{array}{llll}{ }^{1} \boldsymbol{N} & { }^{3} \boldsymbol{N} & { }^{2} \boldsymbol{N}\end{array}\right]$, $\widehat{\boldsymbol{u}}^{\boldsymbol{e}^{T}}=\left\{\begin{array}{lll}{ }^{e} \hat{\boldsymbol{u}}^{1} & { }^{e} \hat{\boldsymbol{u}}^{3} & { }^{e} \hat{\boldsymbol{u}}^{2}\end{array}\right\}$. The expression for ${ }^{1} \boldsymbol{N},{ }^{3} \boldsymbol{N},{ }^{2} \boldsymbol{N},{ }^{e} \hat{\boldsymbol{u}}^{1},{ }^{e} \hat{\boldsymbol{u}}^{3}$ and ${ }^{e} \hat{\boldsymbol{u}}^{2}$ are given in Appendix A. The considered three-nodded element and corresponding nodal variables are shown in Fig. 3.

It should be pointed here that the linear or cubic Lagrangian shape functions may be used for interpolating of $u_{0 i}$ and $\omega_{i}(i=t, m, b)$. However, previous published results [30-32] show that the selection of the same order of interpolation for $w_{, x}$ and $\omega_{i}$ in the expression of transverse shear strain $\left(\gamma_{13}\right)_{i}$, prevents from the appearance of shear locking phenomenon.

The kinematic relations considered for the constituent elements of the FICSP (Eqs. (1)) can be written as the following matrix form:

$\boldsymbol{U}_{t}=\boldsymbol{A}_{t} \boldsymbol{u}$

$\boldsymbol{U}_{m}=\boldsymbol{A}_{m} \boldsymbol{u}$

$\boldsymbol{U}_{b}=\boldsymbol{A}_{b} \boldsymbol{u}$

where $\boldsymbol{U}_{i}=\left\{U_{i}^{(k)} W_{i}^{(k)}\right\}^{T}$, and

$\mathrm{A}_{t}=\left[\begin{array}{llllllc}0 & \left(\left(\frac{h_{t}}{\pi}\right) \sin \left(\frac{\pi z t}{h_{t}}\right)-z_{t}\right) \frac{d}{d x} & 0 & 0 & 0 & 1 & \left(\frac{h_{t}}{\pi}\right) \sin \left(\frac{\pi z t}{h_{t}}\right) \\ 0 & 1 & 0 & 0 & 0 & 0 & 0\end{array}\right]$

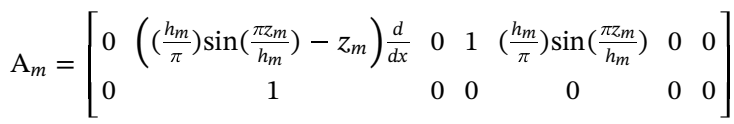

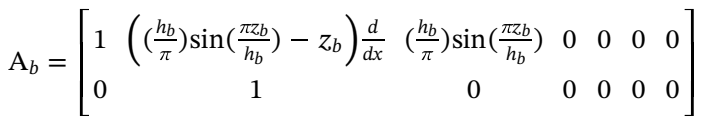

By substituting Eq. (13) into Eq. (14), the vector of global displacements $\boldsymbol{U}_{i}$ can be written with respect to the nodal displacement vector $\widehat{\boldsymbol{u}}^{e}$ :

$\boldsymbol{U}_{i}=\boldsymbol{A}_{i} \boldsymbol{N} \hat{\boldsymbol{u}}^{\boldsymbol{e}}=\boldsymbol{\Omega}_{i} \hat{\boldsymbol{u}}^{\boldsymbol{e}}$

The strain components of FICSP can be rewritten as the below matrix form:

$\varepsilon_{t}=\boldsymbol{C}_{t} \boldsymbol{u}$

$\boldsymbol{\varepsilon}_{m}=\boldsymbol{C}_{m} \boldsymbol{u}$

$\varepsilon_{b}=\boldsymbol{C}_{b} \boldsymbol{u}$

where $\varepsilon_{i}=\left\{\left(\varepsilon_{x x}^{(k)}\right)_{i}\left(\gamma_{x z}^{(k)}\right)_{i}\right\}^{T}$, and

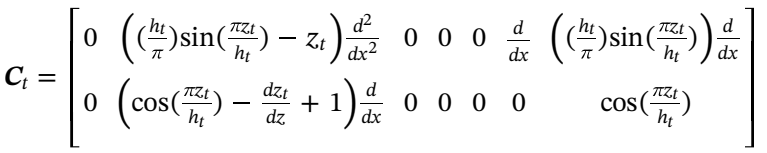


$\boldsymbol{C}_{m}=\left[\begin{array}{cccccc}0 & \left(\left(\frac{h_{m}}{\pi}\right) \sin \left(\frac{\pi z_{m}}{h_{m}}\right)-z_{m}\right) \frac{d^{2}}{d x^{2}} & 0 & \frac{d}{d x}\left(\left(\frac{h_{m}}{\pi}\right) \sin \left(\frac{\pi z_{m}}{h_{m}}\right)\right) \frac{d}{d x} & 0 & 0 \\ 0\left(\cos \left(\frac{\pi z_{m}}{h_{m}}\right)-\frac{d z_{m}}{d z}+1\right) \frac{d}{d x} & 0 & 0 & \cos \left(\frac{\pi z_{m}}{h_{m}}\right) & 0 & 0\end{array}\right]$

$\boldsymbol{C}_{b}=\left[\begin{array}{ccccccc}\frac{d}{d x} & \left(\left(\frac{h_{b}}{\pi}\right) \sin \left(\frac{\pi z_{b}}{h_{b}}\right)-z_{b}\right) \frac{d^{2}}{d x^{2}} & \left(\left(\frac{h_{b}}{\pi}\right) \sin \left(\frac{\pi z_{b}}{h_{b}}\right)\right) \frac{d}{d x} & 0 & 0 & 0 & 0 \\ 0 & \left(\cos \left(\frac{\pi z_{b}}{h_{b}}\right)-\frac{d z_{b}}{d z}+1\right) \frac{d}{d x} & \cos \left(\frac{\pi z_{b}}{h_{b}}\right) & 0 & 0 & 0 & 0\end{array}\right]$

Substituting of Eq. (13) into Eqs. (16) yields:

$\varepsilon_{i}=C_{i} \boldsymbol{N} \hat{\boldsymbol{u}}^{e}=\Psi_{i} \hat{\boldsymbol{u}}^{e}$

Based on Eqs. (3) and (4), the slips appeared at the interface between the concrete wythe and insulation layer can be written as the following matrix form:

$S_{t m}=\left[0\left(\frac{h_{m}}{2}+\frac{h_{t}}{2}-\frac{h_{t}}{\pi}-\frac{h_{m}}{\pi}\right) \frac{d}{d x} 0-1-\frac{h_{m}}{\pi} 1-\frac{h_{t}}{\pi}\right]=\boldsymbol{A}_{t m}^{\text {spring }} \boldsymbol{u}$

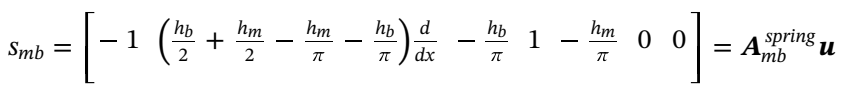

Substituting of Eq. (13) into the above equations gives:

$s_{t m}=\boldsymbol{A}_{t m}^{s p r i n g} \boldsymbol{u}=\boldsymbol{A}_{t m}^{\text {spring }} \boldsymbol{N} \hat{\boldsymbol{u}}^{\boldsymbol{e}}=\Upsilon_{t m} \hat{\boldsymbol{u}}^{\boldsymbol{e}}$

$S_{m b}=\boldsymbol{A}_{m b}^{\text {spring }} \boldsymbol{u}=\boldsymbol{A}_{m b}^{\text {spring }} \boldsymbol{N} \hat{\boldsymbol{u}}^{\boldsymbol{e}}=\Upsilon_{m b} \hat{\boldsymbol{u}}^{\boldsymbol{e}}$

By introducing the interpolation functions (Eq. (13)) in the virtual work principle (Eq. (12)), the element load vector is obtained as

$\boldsymbol{F}^{e}=\sum^{n c} \int_{-1}^{+1} \int_{z_{k}}^{z_{k+1}} \boldsymbol{\Omega}_{i}^{T} \overline{\boldsymbol{P}}_{i}^{V} d z \frac{d x}{d \xi} d \xi+\int_{-1}^{+1} \boldsymbol{\Omega}_{i}^{T} \overline{\boldsymbol{P}}_{i} \frac{d x}{d \xi} d \xi$

After introducing the constitutive relations (Eqs. (5)(11)) as well as the strain-nodal variables relations (Eq. (17)) in the virtual work principle, the following expression is obtained for the element stiffness matrix:

$$
\begin{aligned}
\boldsymbol{K}^{e}= & \sum^{n_{t}} \int_{-1}^{+1} \int_{z^{k}}^{z^{k+1}} \boldsymbol{\Psi}_{t}^{T} \boldsymbol{D}_{c}^{(k)} \boldsymbol{\Psi}_{t} d z \frac{d x}{d \xi} d \xi \\
& +\sum^{n_{m}} \int_{-1}^{+1} \int_{z^{k}}^{z^{k+1}} \boldsymbol{\Psi}_{m}^{T} \boldsymbol{D}_{m}^{(k)} \boldsymbol{\Psi}_{m} d z \frac{d x}{d \xi} d \xi \\
& +\sum^{n_{b}} \int_{-1}^{+1} \int_{z^{k}}^{z^{k+1}} \boldsymbol{\Psi}_{b}^{T} \boldsymbol{D}_{c}^{(k)} \boldsymbol{\Psi}_{b} d z \frac{d x}{d \xi} d \xi \\
& +\sum^{n_{s t}} \int_{-1}^{+1} \int_{z^{k}}^{z^{k+1}} \boldsymbol{\Psi}_{t}^{T} \boldsymbol{D}_{s}^{(k)} \boldsymbol{\Psi}_{t} d z \frac{d x}{d \xi} d \xi \\
& +\sum^{n_{s b}} \int_{-1}^{+1} \int_{z^{k}}^{z^{k+1}} \boldsymbol{\Psi}_{b}^{T} \boldsymbol{D}_{s}^{(k)} \boldsymbol{\Psi}_{b} d z \frac{d x}{d \xi} d \xi+\int_{-1}^{+1} \bar{k} \Upsilon_{t m}^{T} \Upsilon_{t m} \frac{d x}{d \xi} d \xi \\
& +\int_{-1}^{+1} \bar{k} \Upsilon_{m b}^{T} \Upsilon_{m b} \frac{d x}{d \xi} d \xi
\end{aligned}
$$

$n_{t}, n_{m}, n_{b}, n_{s b}$ and $n_{s t}$ are the number of sub-layers of top concrete wythe, insulation layer, bottom concrete wythe, top equivalent steel layer, and bottom equivalent steel layer, respectively. $\xi$ is the local coordinate of FICSP elements. Summing the element contributions, the following final nonlinear system of equations are obtained from the application of the virtual work principle:

$\left[\boldsymbol{K}_{T}\right]\{\widehat{\boldsymbol{u}}\}=\left\{\boldsymbol{F}_{T}\right\}$

where

$\left[\boldsymbol{K}_{\boldsymbol{T}}\right]=\sum^{e} \boldsymbol{K}^{e}, \quad\left\{\boldsymbol{F}_{\boldsymbol{T}}\right\}=\sum^{e} \boldsymbol{F}^{e},\{\hat{\boldsymbol{u}}\}=\sum^{e} \boldsymbol{u}^{e}$

Since the nonlinear behavior of insolation layer, steel and concrete is considered in the formulation, the above system of equations are nonlinear and should be solved using the usual incremental-iterative methods. By assuming that the estimate solution at the ith iteration is $\left\{\hat{\boldsymbol{u}}^{i}\right\}$, the solution at the next step can be estimated as below using the first-order Taylor series:

$\left\{\hat{\boldsymbol{u}}^{i+1}\right\}=\left\{\hat{\boldsymbol{u}}^{i}\right\}+{ }^{(m)}\left\{\Delta \hat{\boldsymbol{u}}^{i+1}\right\}$

In the above equation, ${ }^{(m)}\left\{\Delta \hat{\boldsymbol{u}}^{i+1}\right\}$ is the $m$ th estimation to the incremental vector displacement $\left\{\Delta \hat{\boldsymbol{u}}^{i+1}\right\}$. It can be obtained from the resolution of the linear system:

${ }^{(m-1)}\left[\boldsymbol{K}_{\boldsymbol{T}}^{i+1}\right]^{(m)}\left\{\Delta \hat{\boldsymbol{u}}^{i+1}\right\}=\left\{\Delta \boldsymbol{F}_{\boldsymbol{T}}^{i+1}\right\}$

where

$$
\begin{aligned}
(m-1)\left[\boldsymbol{K}_{\boldsymbol{T}}^{i+1}\right]= & \sum^{e}\left(\sum^{n_{t}} \int_{-1}^{+1} \int_{z^{k}}^{z^{k+1}} \boldsymbol{\Psi}_{t}^{T *} \boldsymbol{D}_{c}^{(k)} \boldsymbol{\Psi}_{t} d z \frac{d x}{d \xi} d \xi\right. \\
& +\sum^{n_{m}} \int_{-1}^{+1} \int_{z^{k}}^{z^{k+1}} \boldsymbol{\Psi}_{m}^{T *} \boldsymbol{D}_{m}^{(k)} \boldsymbol{\Psi}_{m} d z \frac{d x}{d \xi} d \xi \\
& +\sum^{n_{b}} \int_{-1}^{+1} \int_{z^{k}}^{z^{k+1}} \boldsymbol{\Psi}_{b}^{T *} \boldsymbol{D}_{c}^{(k)} \boldsymbol{\Psi}_{b} d z \frac{d x}{d \xi} d \xi \\
& +\sum^{n_{s t}} \int_{-1}^{+1} \int_{z^{k}}^{z^{k+1}} \boldsymbol{\Psi}_{t}^{T *} \boldsymbol{D}_{s}^{(k)} \boldsymbol{\Psi}_{t} d z \frac{d x}{d \xi} d \xi \\
& +\sum^{n_{s b}} \int_{-1}^{+1} \int_{z^{k}}^{z^{k+1}} \boldsymbol{\Psi}_{b}^{T *} \boldsymbol{D}_{s}^{(k)} \boldsymbol{\Psi}_{b} d z \frac{d x}{d \xi} d \xi+\int_{-1}^{+1} \bar{k} \Upsilon_{t m}^{T} \Upsilon_{t m} \frac{d x}{d \xi} d \xi \\
& \left.+\int_{-1}^{+1} \bar{k} \Upsilon_{m b}^{T} \Upsilon_{m b} \frac{d x}{d \xi} d \xi\right)
\end{aligned}
$$

Based on the history of stress at each sub-layer element, ${ }^{*} \boldsymbol{D}_{c}^{(k)}$ may denote the elastic moduli matrix $\boldsymbol{D}_{c}^{(k)}$ or the incremental moduli matrix ${ }^{t} \boldsymbol{D}_{c}^{(k)}$. The similar definitions are exist for the matrices ${ }^{*} \boldsymbol{D}_{s}^{(k)}$ and ${ }^{*} \boldsymbol{D}_{m}^{(k)}$.

\section{Numerical results}

In this section, some FICSPs were analyzed until failure stage by means of the presented 1D nonlinear finite element model. In order to assess the accuracy of the present numerical model in predicting the structural responses of FICSP systems, the obtained numerical data were compared with the full-scale experimental data, results of the 3D finite element (ABAQUS) analysis and the analytical results reported in open literature.

\subsection{Example 1}

A simply supported FICSP with span $3.05 \mathrm{~m}$ was analyzed by means of the present nonlinear finite element model. It is submitted to a uniform pressure. The geometrical characteristics and cross-section properties of the considered FICSP are shown in Fig. 4. The insulation layer is made of XEPS material with $E_{x x}^{m}=40.9 \mathrm{MPa}$ and $G_{x z}^{m}=12.7 \mathrm{MPa}$. Table 1shows the mechanical properties assumed for the longitudinal steel rebar and concrete wythes. Three different values $\bar{k}=952 \mathrm{kN} / \mathrm{m}^{3}$, $8490 \mathrm{kN} / \mathrm{m}^{3}$, and $374,678 \mathrm{kN} / \mathrm{m}^{3}$ are assumed for the stiffness of shear ties.

Due to the structural symmetry of the considered FICSP system, only the half of it was modeled. Based on the convergence mesh study, the FICSP was axially discretized into 20 elements with equal length. The applied boundary conditions at the support of FICSP model is $w=0$. At the middle of FICSP system, the considered boundary conditions are $w_{, x}=u_{0 b}=u_{0 m}=u_{0 t}=\omega_{b}=\omega_{m}=\omega_{t}=0$. The cross-section of FICSP was also divided into 20 sub-layers. Seven sub-layers were assumed for each concrete wythe while the insolation layer was divided into six sublayers. As shown in Fig. 5, the selected number of sub-layers is adequate for a nonlinear finite element analysis. Although the kinematics relation given in (1) is written individually for each constituent layer (and not for sub-layers), the sub-layer discretization is also needed due to the consideration of nonlinear behavior of material. In contrast to concrete 


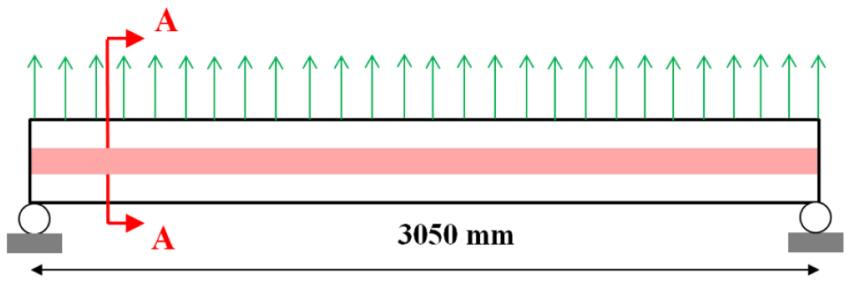

(a)

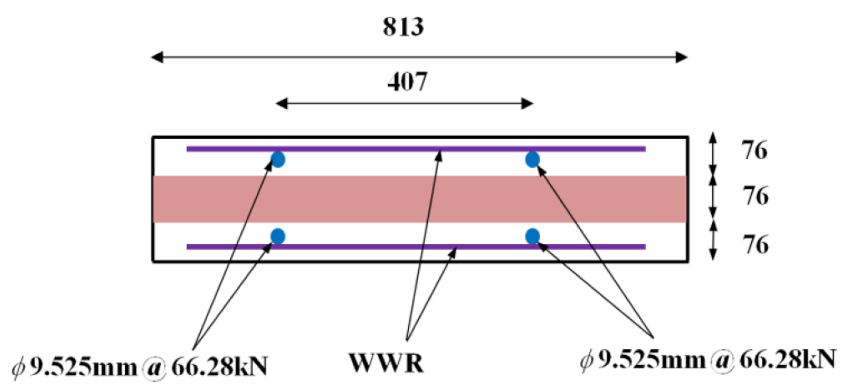

(b)

Fig. 4. Geometrical characteristics of considered FICSP of example 1: (a) loads and boundary conditions (b) cross-section details-unit (mm).

Table 1

Mechanical characteristics of concrete wythes and steel rebar - Example 1.

\begin{tabular}{lll}
\hline Mechanical property & Concrete wythes & Steel rebar \\
\hline Modulus of elasticity (GPa) & 36 & 200 \\
Yield strength (MPa) & - & 480 \\
Compressive strength (MPa) & 49 & - \\
Tensile strength (MPa) & 2.8 & - \\
Poisson's ratio & 0.18 & 0.3 \\
\hline
\end{tabular}

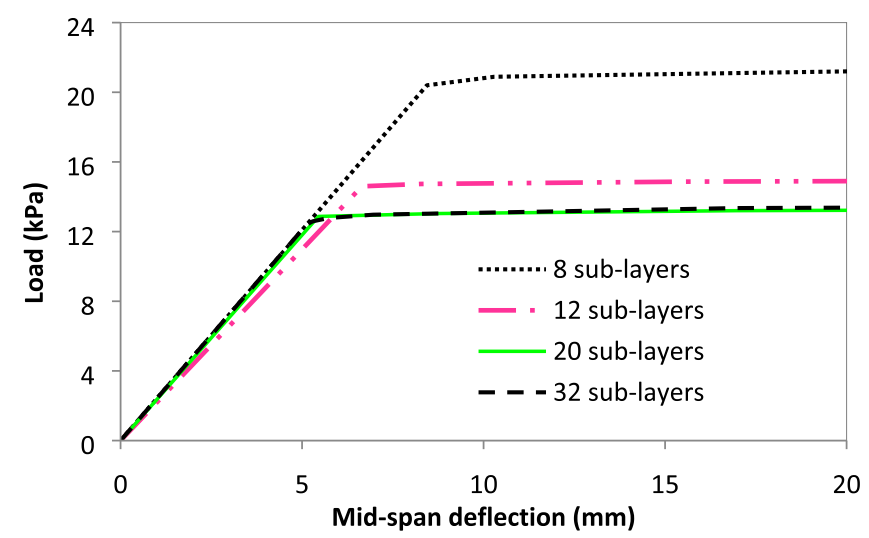

Fig. 5. Effect of the number of cross-section sub-layers on the mid-span deflection of FICSP $\left(\bar{k}=8490 \mathrm{kN} / \mathrm{m}^{3}\right)$.

layer, the foam insulation layer does not experience significant stress and it will remain in the elastic regime. To this reason, the lower number of sub-layer division is assumed for it. For different values of shear ties' stiffness, the mid-span deflection of FICSP under different pressure state is depicted in Fig. 6. The pressure-slip diagram at the end of the FICSP is also shown in Fig. 7. The depicted graphs of Figs. 6 and 7 indicate that the stiffness of shear ties has a remarkable effect on the structural responses of FICSP systems. It should be pointed here that the FICSP system of this example has previously been investigated by Naito et al. [2] via experimental tests. For each FICSP system with a distinct $\bar{k}$,

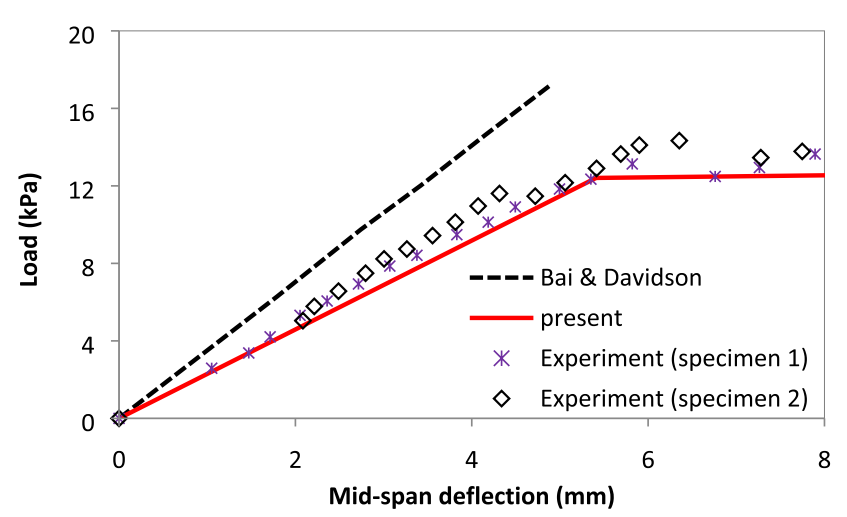

(a)
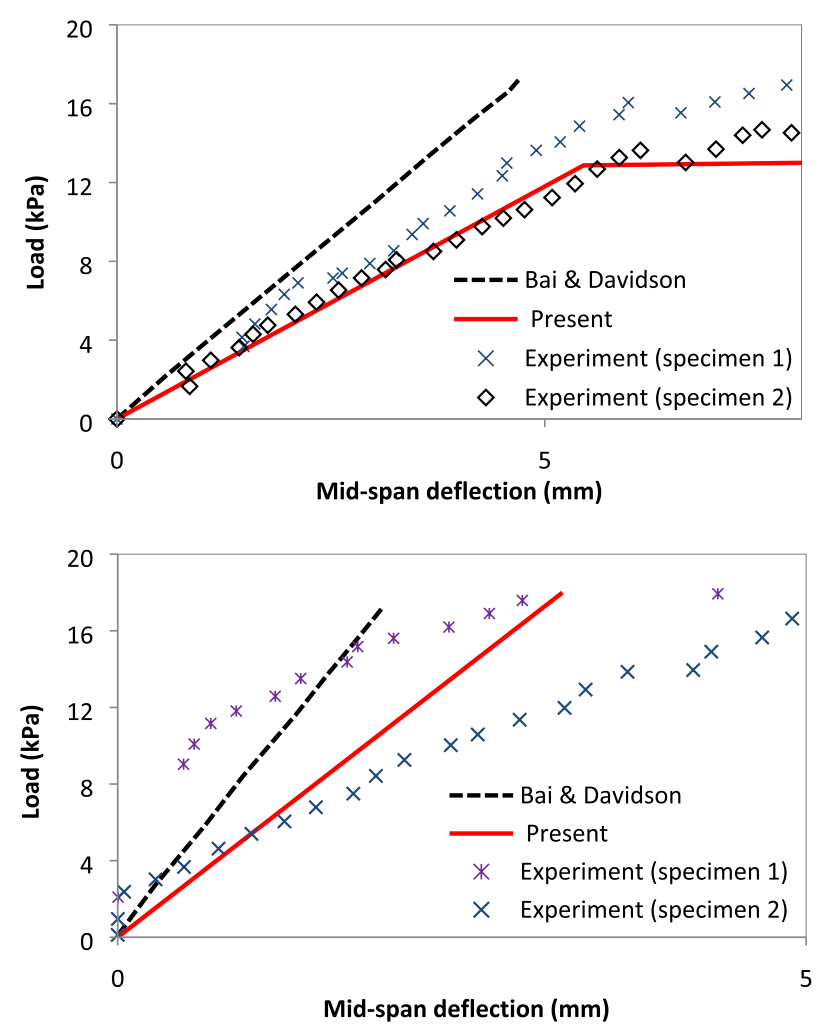

(c)

Fig. 6. Mid-span deflection of FICSP versus the applied pressure: (a) $\bar{k}=952 \mathrm{kN} / \mathrm{m}^{3}$, (b) $8490 \mathrm{kN} / \mathrm{m}^{3}$, (c) $374,678 \mathrm{kN} / \mathrm{m}^{3}$.

two similar specimens were fabricated and tested by Naito and colleagues in their laboratory. The results corresponding to these two specimens are shown in depicted graphs of Figs. 6 and 7. The considered FICSPs of the present example have also been analyzed by Bai and Davidson [23] using an analytical elastic model. In Figs. 6 and 7, the results of these researchers are also shown and compared with the present results. It can be seen that the present finite element model gives results which are in good agreement with reported experimental data. In comparison to the analytical results of Bai and Davidson, the results of present model are more close to the experimental results. In contrast to the analytical model of Bai and Davidson which assumes a linear elastic behavior for materials, the present finite element model considers the nonlinear behavior of all constituent elements of the FICSPs. 


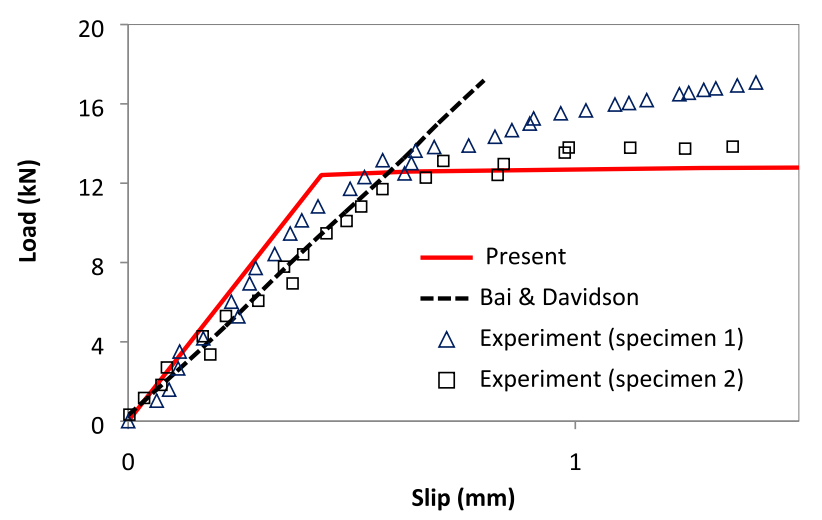

(a)

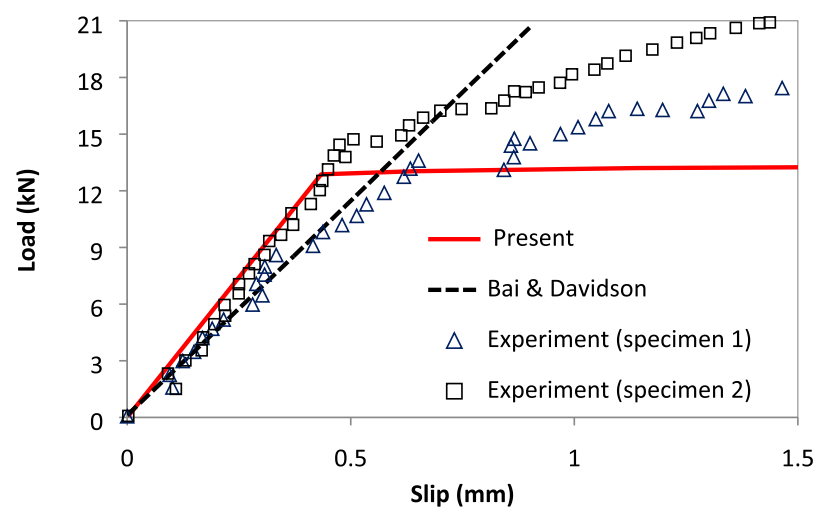

(b)

Fig. 7. Pressure-slip history at the end of the FICSP: (a) $\bar{k}=952 \mathrm{kN} / \mathrm{m}^{3}$, (b) $8490 \mathrm{kN} / \mathrm{m}^{3}$.

\subsection{Example 2}

The structural response of a FICSP system till collapse stage is evaluated in this section using the proposed nonlinear finite element model. The geometrical and structural details of considered FICSP system are shown in Fig. 8. The FICSP is simply supported and is under the action of a uniform pressure. Table 2 gives the mechanical properties corresponding to longitudinal steel rebar and concrete wythes. The insulation layer is made of XEPS material. The distributed equivalent stiffness of shear ties is approximated as $\bar{k}=28,310 \mathrm{kN} / \mathrm{m}^{3}$ [33].

The pressure-deflection graph of the FICSP system predicted by the nonlinear finite element model of present study is depicted in Fig. 9. In this figure, the static test results performed at the University of Missouri [34], and the analytical results of Kang [27] based on the ACI standard design code are also shown for more comparison. It is seen that the results obtained from the nonlinear finite element model of present study are in good agreement with the reported experimental data. It can be also observed that the analytical methods based on ACI standard design code can only predict the fully composite and non-composite behavior of FICSPs systems. Thus, such methods are not able to model the partial composite behavior of FICSPs. As seen in Fig. 9, the fully composite and non-composite behavior make, respectively, the upper and lower boundaries of the capacity curve of the FICSPs.

In the following, the accuracy of presented finite element
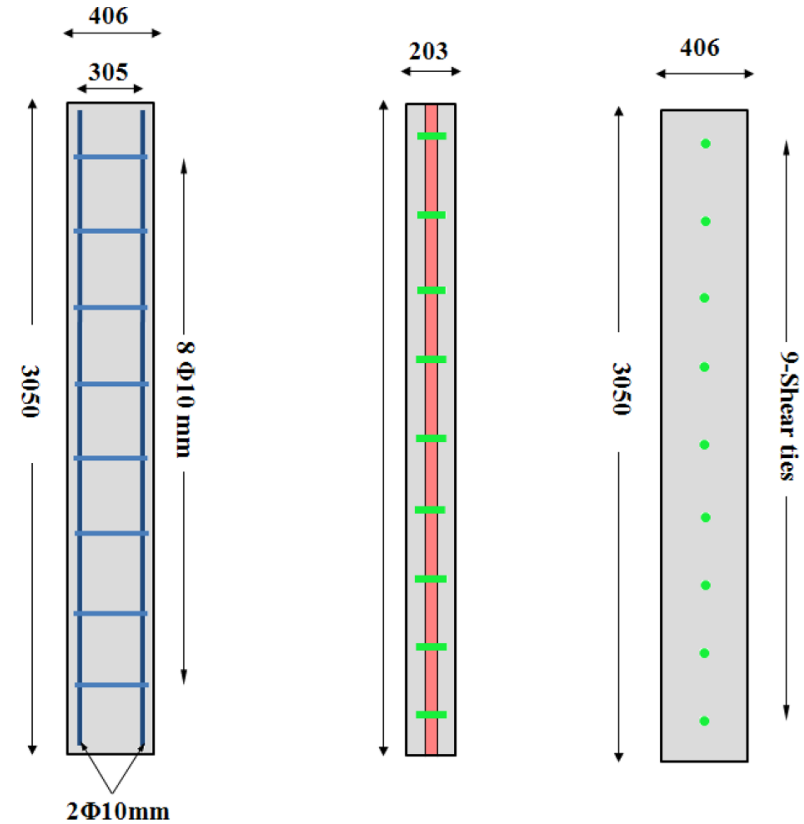

Wythe's Reinforcing

Side Elevation Connector Layout

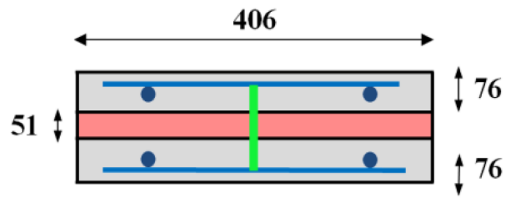

Cross-Section

Fig. 8. Geometrical characteristics and cross-section details of FICSP: unit (mm).

Table 2

Mechanical characteristics of concrete wythes and steel rebar - Example 2.

\begin{tabular}{lll}
\hline Mechanical property & Concrete wythes & Steel rebar \\
\hline Modulus of elasticity (GPa) & 24.8 & 200 \\
Yield strength (MPa) & - & 480 \\
Compressive strength (MPa) & 34 & - \\
Tensile strength (MPa) & 2.8 & - \\
Poisson's ratio & 0.18 & 0.3 \\
\hline
\end{tabular}

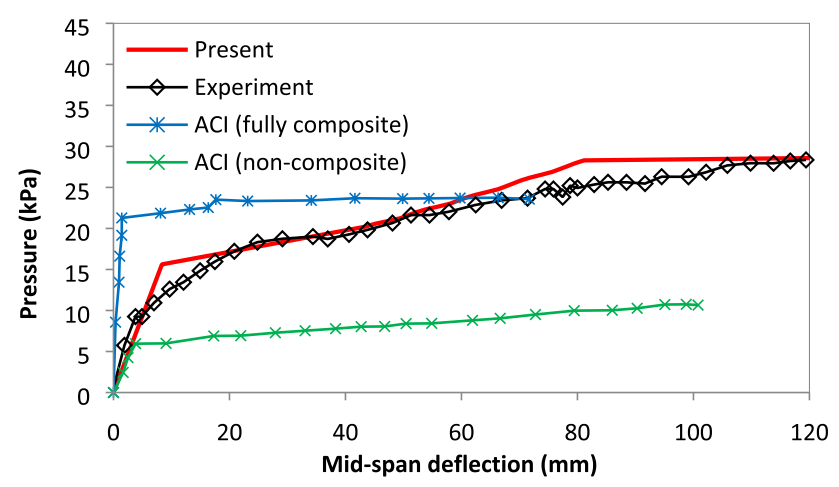

Fig. 9. Pressure-deflection history of FICSP-example 2. 


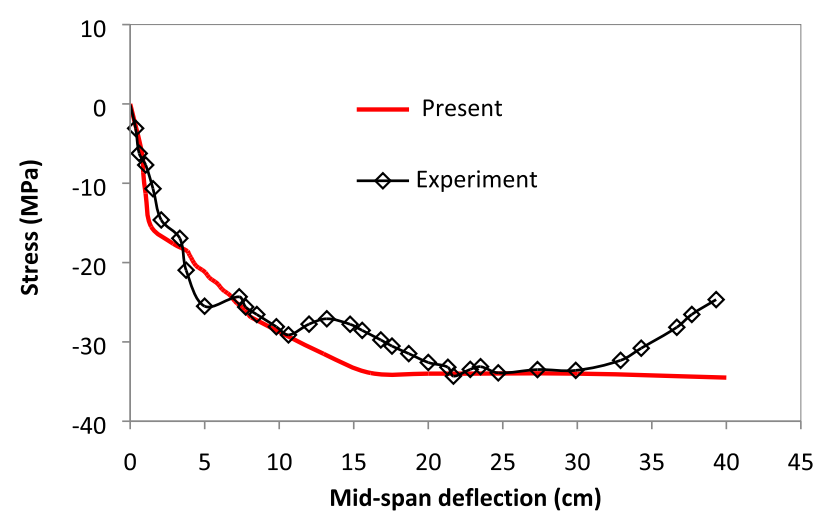

(a)

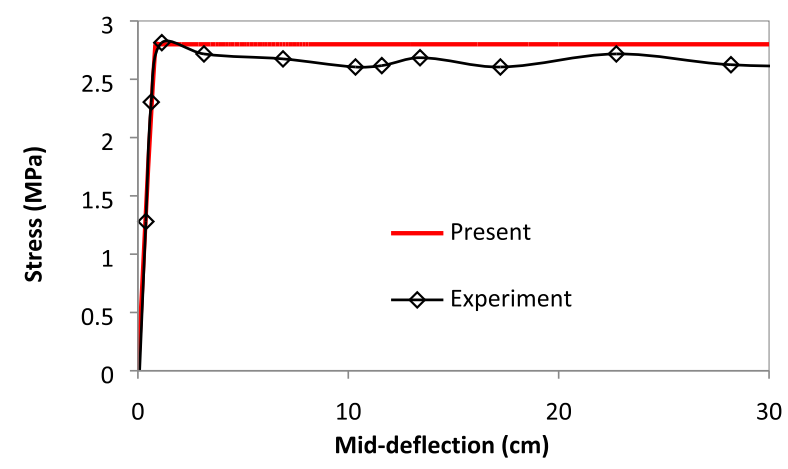

(b)

Fig. 10. Stress-deflection history at the mid-span of FICSP: (a) upper concrete wythe, (b) lower concrete wythe.

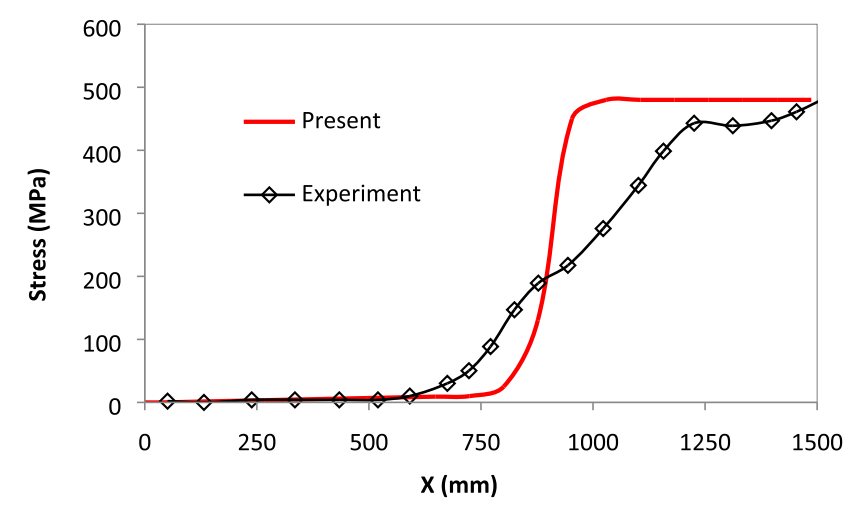

Fig. 11. Variations of axial stress in upper steel rebar at the ultimate load stage.

formulation in predicting the detailed (local) structural behavior of FICSP's components is evaluated. To this aim, variations of mid-span axial stress at upper and lower concrete wythes against the mid-span deflection are shown in Fig. 10. Fig. 11 shows distributions of axial (inplane) stress in upper steel rebar at the ultimate pressure stage. Finally, axial stress-strain history on insulation layer at the middle of span is also shown in Fig. 12.

It can be seen from Figs. 10-12 that there exist a good correlation between the experimental and present results in predicting the local structural behavior of FICSP systems. Concerning the numerical results corresponding to the axial stress in upper steel rebar (Fig. 11), it can be seen that the slope in the middle part of graph is not the same as the experiment. This discrepancy may be due to neglecting the structural effect of WWR in the 1D finite element formulation of the present model. Indeed, that part of wire mesh which is transverse to the

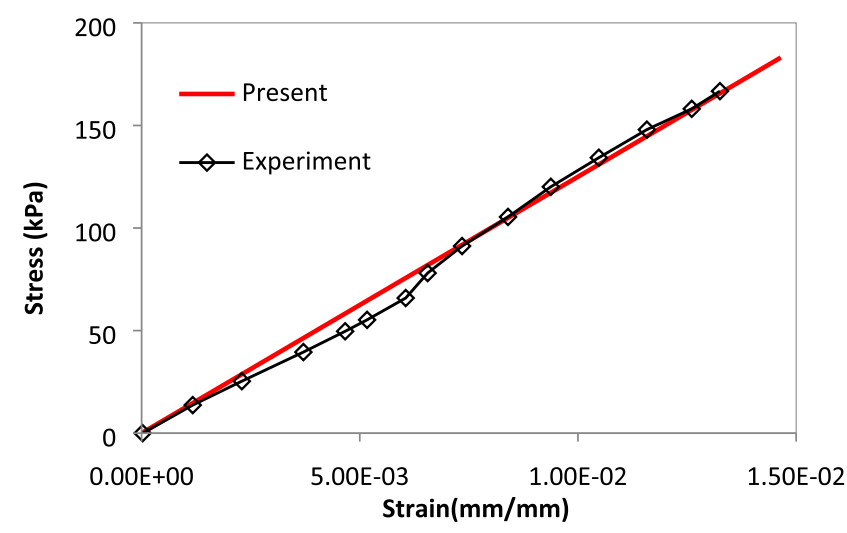

Fig. 12. Axial stress-strain history on insulation layer at mid-span.

longitudinal rebar cannot be modeled in the framework of a 1D finite element model. Assuming a perfect bonding between the longitudinal rebar and surrounding concrete may be other reason which leads to the difference between the experimental and present results.

The above obtained numerical results confirm that the introduced finite element formulation of the present study is an appropriate tool for global-local structural analysis of FICSP systems.

\subsection{Example 3}

As a final example, a cantilever FICSP system till failure stage was analyzed via the nonlinear finite element formulation introduced in Section 4. The length of the considered FICSP is $4 \mathrm{~m}$ and it is under the action of a distributed pressure. The cross-section details and the mechanical properties of the constituent elements of the considered FICSP system of the present example are the same as example 1 . The distributed equivalent stiffness of shear ties which provides the connectivity between the upper and lower concrete wythes is assumed to be $\bar{k}=0 \mathrm{kN} / \mathrm{m}^{3}$ (non-composite action), $123 \times 10^{3} \mathrm{kN} / \mathrm{m}^{3}$ (partially composite action), and $123 \times 10^{6} \mathrm{kN} / \mathrm{m}^{3}$ (fully composite action).

In Fig. 13, variations of the reaction force against the tip deflection of FICSP are depicted for three different interface conditions (i.e. partially composite, non-composite, and fully composite actions). It is seen again that the ultimate capacity of FICSP system is extremely dependent on the stiffness of shear ties. In Fig. 13, the present results were compared with nonlinear 3D finite element results. ABAQUS software was employed for carrying out a 3D finite element analysis. Concrete whythes and insulation layer are modeled using 8-node brick elements (C3D8R). Longitudinal steel rebar as well as the WWRs are modeled

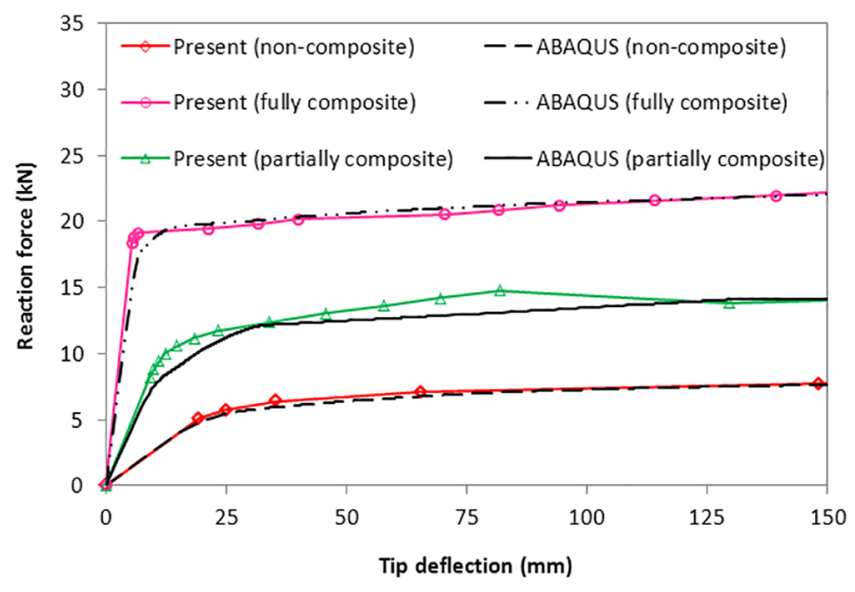

Fig. 13. Tip deflection of cantilever FICSP versus the reaction force. 


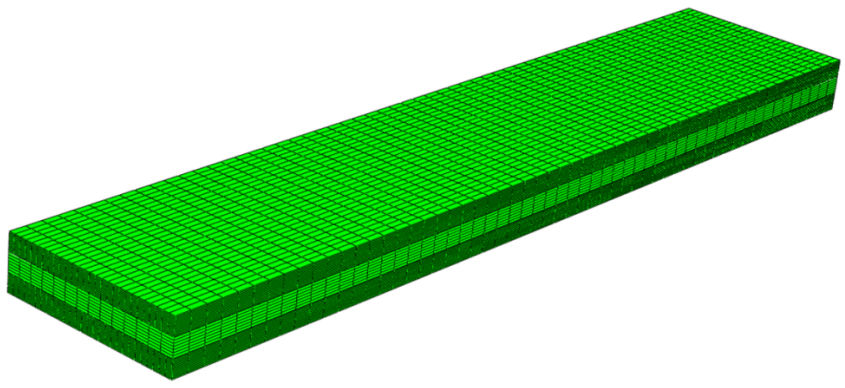

Fig. 14. The refined mesh used for 3D finite element model (ABAQUS).

Table 3

The values of parameters used for the CDP model.

\begin{tabular}{lllll}
\hline$\psi$, dilation angle & $e$, eccentricity & $f_{b 0} / f_{c}$ & $K_{c}$ & $\mu$, viscosity parameter \\
\hline $30^{\circ}$ & 0.5 & 1.16 & 0.667 & 0.0001 \\
\hline
\end{tabular}

using 2-node truss elements. The refined mesh used for 3D finite element model is shown in Fig. 14. The number of elements used for meshing each concrete whyth is $6 \times 30 \times 50$. The mesh of insulation layer includes $5 \times 30 \times 50$ brick elements. Longitudinal steel rebar and WWR were divided into 50 and 10 elements, respectively. Since longitudinal steel rebar and the WWRs are embedded in the concrete layers, a perfect bond is assumed at the interface between them. Due to the occurrence of slip at the interfaces between the concrete and insulation layers, assumption of a perfect bond is not correct for describing the interfacial behavior between them. In order to capture the partial composite action in the 3D model of considered FICSP, traction-separation laws (cohesive behavior) are used for describing the interfacial behavior between the concrete wythes and insulation layer. Tractionseparation laws describe the interaction between two surfaces by defining a relative displacement at each contact point. For more details
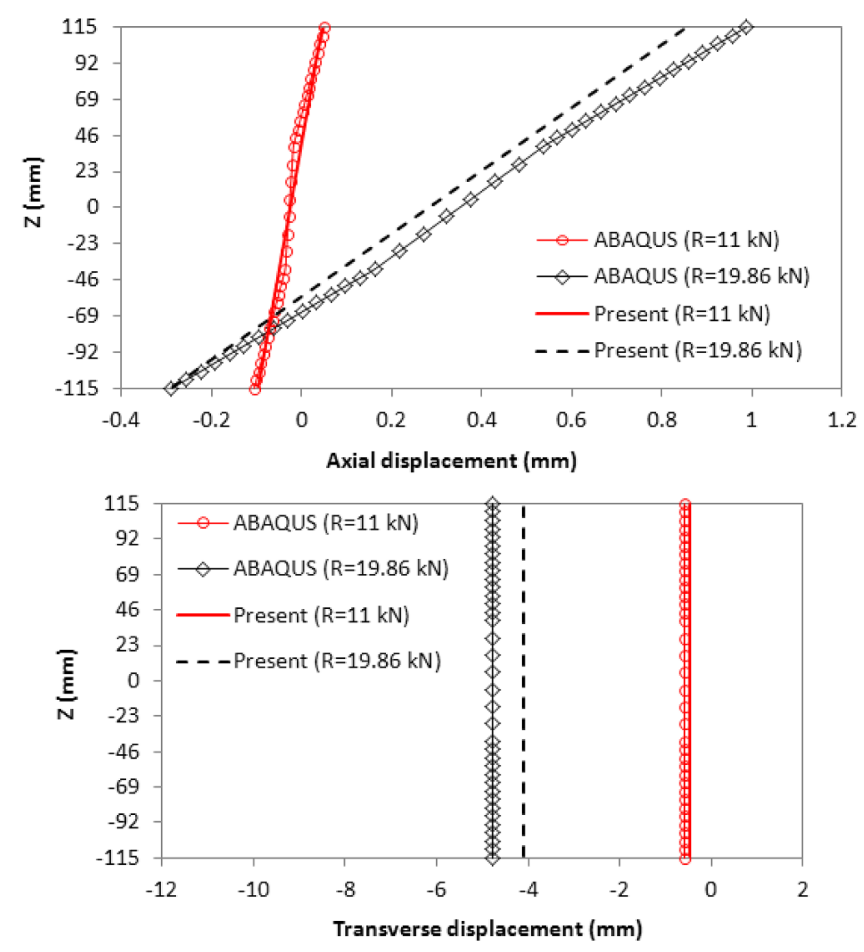

about interfacial traction-separation law, interested readers can refer to [35]. The ideal elasto-plastic and concrete damage plasticity (CDP) models are respectively employed for representing the material nonlinearity of steel and concrete. CDP uses concepts of isotropic damaged elasticity in combination with isotropic tensile and compressive plasticity to represent the inelastic behavior of concrete. The material parameters used for the CDP model are given in Table 3. The expressions corresponding to yield function of the CDP model are given in Appendix A. The present finite element model estimates the maximum load capacity of the cantilever FICSP in non-composite, partially composite and fully composite conditions as $7.74 \mathrm{kN}, 14.80 \mathrm{kN}$, and $21.92 \mathrm{kN}$, respectively. In case of 3D finite element analysis, the aforementioned values are $7.63 \mathrm{kN}, 14.15 \mathrm{kN}$ and $22.05 \mathrm{kN}$. The percent error between the ABAQUS and present results is less than 4.5. It is worthy to be pointed here that the converged mesh of ABAQUS model has about 109,500 DOFs while this value for the 1D finite element formulation of the present study is only 288 DOFs. This comparison proves the 1D finite element formulation introduced in the present study is an efficient tool for nonlinear structural analysis of FICSP systems.

Through-the-thickness distributions of stress and displacement components of FICSP at a section with distance $1 \mathrm{~m}$ from the fixed end are depicted in Figs. 15-17. Note that the transverse shear stress was calculated at the post-processing level by integrating from equilibrium equations. For comparison purposes, the numerical results are also given in Table 4. It can be observed from depicted graphs of Figs. 15-17 that the present finite element formulation has a good accuracy in predicting the local structural behavior of FICSP structures. The small discrepancies between the present and 3D finite element results is mainly due to difference in employed constitutive law used for modeling the nonlinear demeanor of concrete materials. In can be observed from Figs. 15-17 that the interface properties between concrete and foam (i.e. $\bar{k}$ ) has a significant influence on the local structural responses of FICSP systems. For low values of $\bar{k}$, significant slip occurs at the interface between concrete wythe and foam layer. This slip reduces with increasing of shear ties' stiffness so that for $\bar{k}=123 \times 10^{6} \mathrm{kN} / \mathrm{m}^{3}$
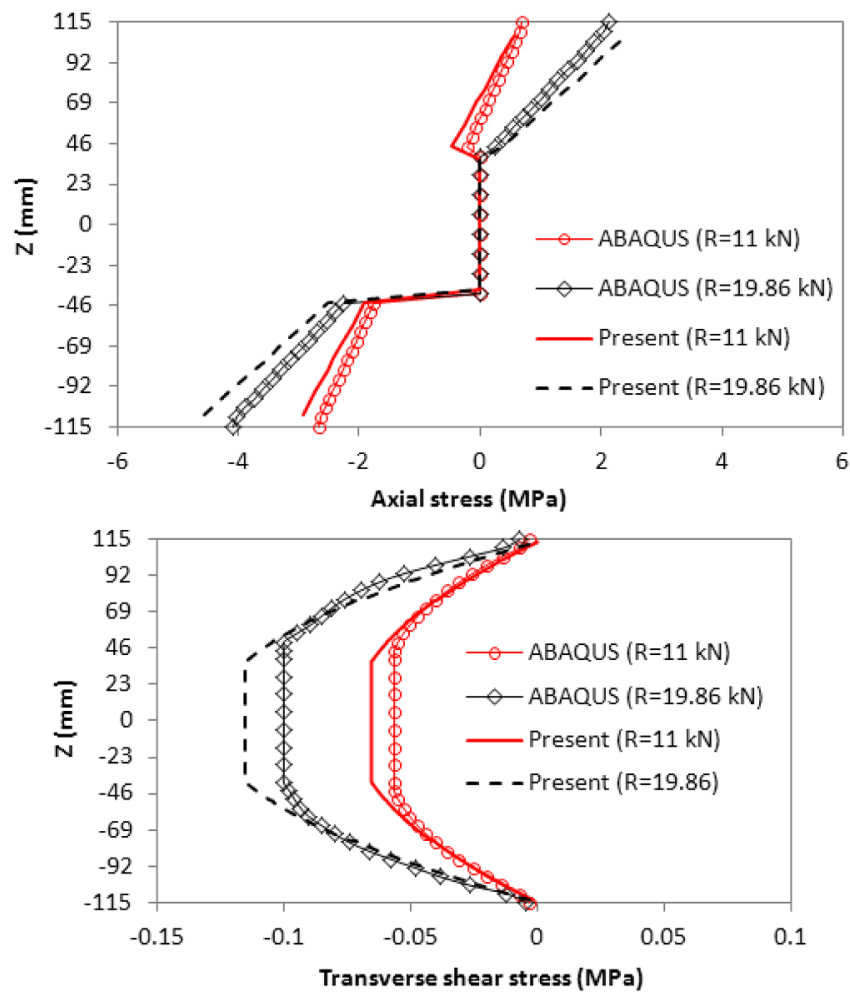

Fig. 15. Through-the-thickness distributions of displacement and stress components for cantilever FICSP: fully composite case. 

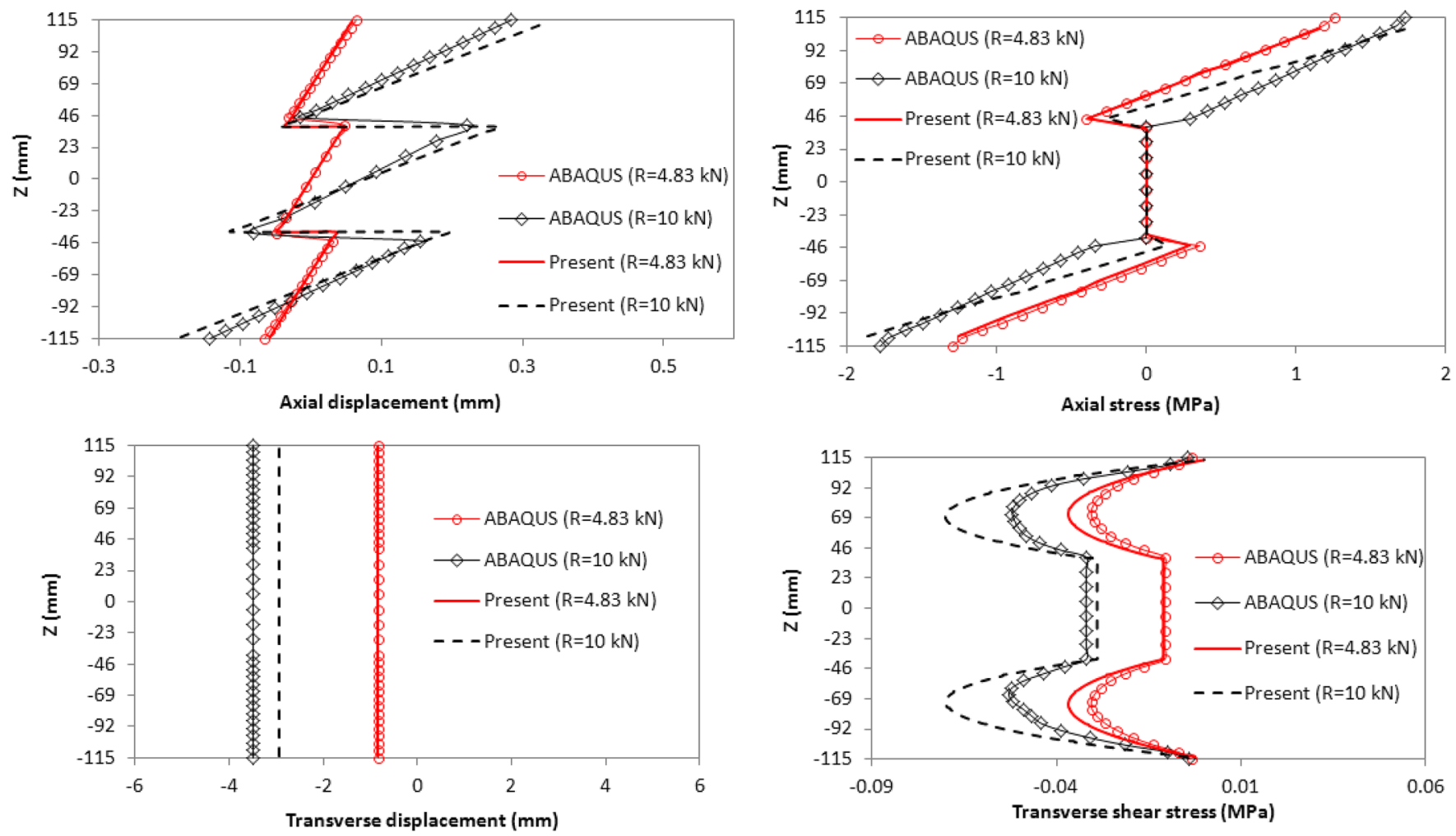

Fig. 16. Through-the-thickness distributions of displacement and stress components at cantilever FICSP: partially composite case.
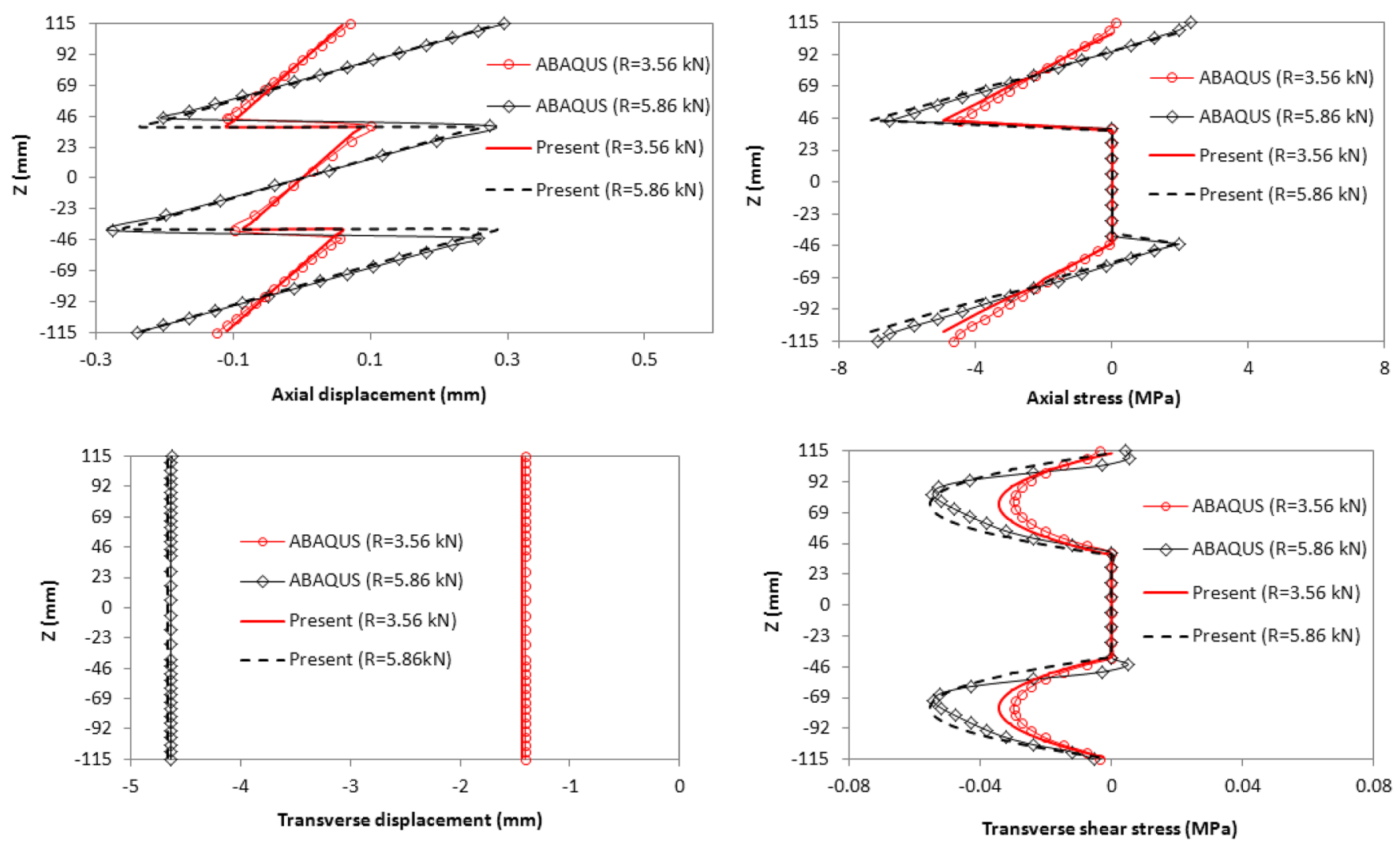

Fig. 17. Through-the-thickness distributions of displacement and stress components at cantilever FICSP: non-composite case. 
Table 4

Displacement (in $\mathrm{mm}$ ) and stress (in MPa) components of the cantilever FICSP- $\mathrm{x}=1000 \mathrm{~mm}$.

\begin{tabular}{|c|c|c|c|c|c|c|}
\hline $\bar{k}\left(k N / m^{3}\right)$ & Load state & Model & $U(1000,-114)$ & $W(1000,0)$ & $\sigma_{11}(500,114)$ & $\sigma_{13}(500,0,0)$ \\
\hline \multirow[t]{4}{*}{$123 \times 10^{6}$} & $\mathrm{R}=11 \mathrm{kN}$ & Present & -0.0959 & -0.4678 & 0.5603 & -0.0655 \\
\hline & & ABAQUS & -0.1050 & -0.5878 & 0.6624 & -0.0564 \\
\hline & $\mathrm{R}=19.86 \mathrm{kN}$ & Present & -0.2864 & -4.1100 & 2.4305 & -0.1152 \\
\hline & & ABAQUS & -0.2880 & -4.7812 & 2.0418 & -0.1000 \\
\hline \multirow[t]{4}{*}{$123 \times 10^{3}$} & $\mathrm{R}=4.83 \mathrm{kN}$ & Present & -0.0580 & -0.8441 & 1.1558 & -0.0110 \\
\hline & & ABAQUS & -0.0653 & -0.8177 & 1.1858 & -0.0107 \\
\hline & $\mathrm{R}=10 \mathrm{kN}$ & Present & -0.1843 & -2.9510 & 1.7306 & -0.0290 \\
\hline & & ABAQUS & -0.1428 & -3.4841 & 1.6719 & -0.0320 \\
\hline \multirow[t]{4}{*}{0} & $\mathrm{R}=3.56 \mathrm{kN}$ & Present & -0.1096 & -1.4399 & 0.0214 & -0.0000 \\
\hline & & ABAQUS & -0.1240 & -1.4058 & 0.0248 & -0.0000 \\
\hline & $\mathrm{R}=5.86 \mathrm{kN}$ & Present & -0.2335 & -4.6698 & 1.8714 & -0.0000 \\
\hline & & ABAQUS & -0.2404 & -4.6334 & 1.9559 & -0.0000 \\
\hline
\end{tabular}

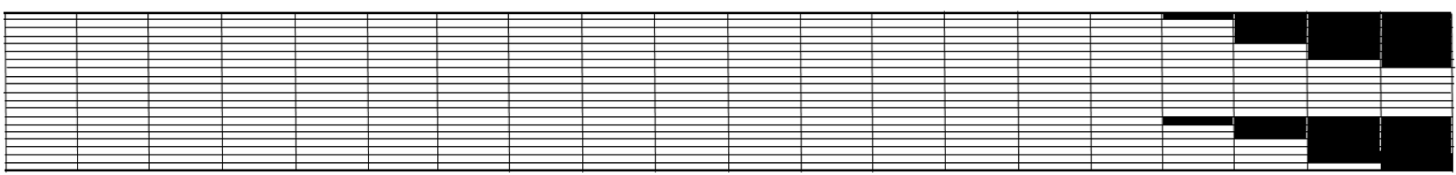

(a)

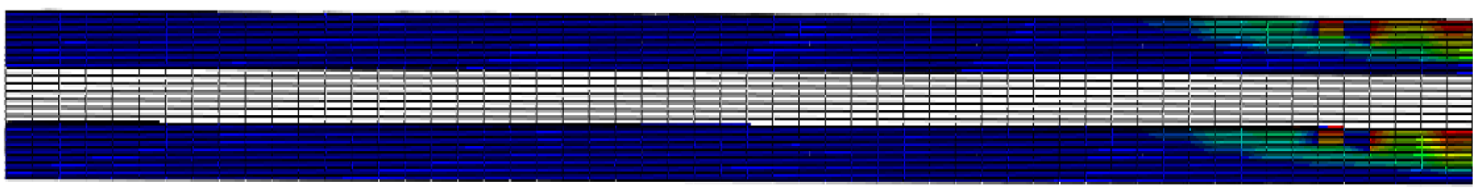

(b)

Fig. 18. Patterns of tensile crack at cantilever FICSP: (a) present finite element model, (b) $3 \mathrm{D}$ finite element model- $(\bar{k}=0)$.

no slip occurs at the interface between layers. When $\bar{k}=123 \times 10^{6} \mathrm{kN} /$ $\mathrm{m}^{3}$, the maximum transverse shear stress situates at the foam layer. With reducing of $\bar{k}$, the value of transverse shear stress in the foam layer reduces. In case of non-composite action, no shear stress appears in the foam layer and maximum shear stress occurs at the center of concrete wythes. Figs. 15-17 show that the through-the-thickness distribution of axial stress is extremely affected by the interface characteristic between foam and concrete. In case of fully composite action, the considered FICSP system is bent as an integral cantilever beam. Top concrete wythe experiences tensile stresses while the lower wythe undergoes compressive stresses. With reducing of $\bar{k}$, every concrete layer is inclined to bend individually.

The tensile crack patterns developed at the concrete wythes are shown in Fig. 18 for non-composite interface condition $(\bar{k}=0)$. In this figure, the tensile crack patterns corresponding to 3D finite element analysis are also shown. It is seen that the patterns of tensile cracks predicted via the present $1 \mathrm{D}$ finite element are similar to those predicted by ABAQUS.

\section{Conclusions}

A simple and efficient displacement-based 1D finite element formulation was introduced for predicting the nonlinear structural behavior of FICSP structures. Non-polynomial expressions are considered for representing the axial displacement of concrete wythes and insolation layer. The assumed displacement field takes into account the transverse shear deformations induced in the constituent components of FICSP structures. Without using any shear correction factor, the presented formulation guarantees the zero conditions of transverse shear stress on exterior plane of concrete wythes. The partial composite action of shear connectors is represented using the concept of spring layer model. In comparison to available 2D and 3D finite element models, the proposed approach is computationally low cost. It has only 22 DOFs per element. The presented finite element can accurately model the fully composite, non-composite and partially composite actions of FICSP structures. The obtained numerical results show that the formulation introduced in this study can estimate both global (deflection, flexural capacity) and local (through-the-thickness distributions of stress components) structural behaviors of FICSP structures at different loading stages with enough accuracy.

Future studies are toward the development of efficient plate/shell elements for predicting the structural responses of FICSP structures till failure stage. 


\section{Appendix A}

Von Mises yield function

$f(\sigma)=\sqrt{\sigma_{x x}^{2}-3 \sigma_{x z}^{2}}-\sigma_{y}$

where $\sigma_{y}$ is the uniaxial yield stress.

Matrix formulation

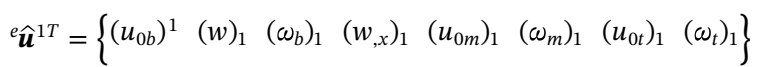

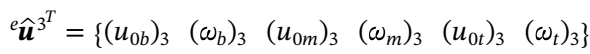

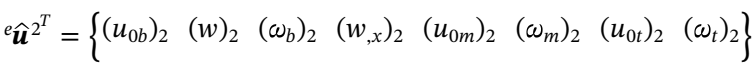

${ }^{1} \boldsymbol{N}=\left[\begin{array}{cccccccc}H_{01} & 0 & 0 & 0 & 0 & 0 & 0 & 0 \\ 0 & H_{1} & 0 & H_{2} & 0 & 0 & 0 & 0 \\ 0 & 0 & H_{01} & 0 & 0 & 0 & 0 & 0 \\ 0 & 0 & 0 & 0 & H_{01} & 0 & 0 & 0 \\ 0 & 0 & 0 & 0 & 0 & H_{01} & 0 & 0 \\ 0 & 0 & 0 & 0 & 0 & 0 & H_{01} & 0 \\ 0 & 0 & 0 & 0 & 0 & 0 & 0 & H_{01}\end{array}\right]$

${ }^{3} \boldsymbol{N}=\left[\begin{array}{cccccc}H_{03} & 0 & 0 & 0 & 0 & 0 \\ 0 & 0 & 0 & 0 & 0 & 0 \\ 0 & H_{03} & 0 & 0 & 0 & 0 \\ 0 & 0 & H_{03} & 0 & 0 & 0 \\ 0 & 0 & 0 & H_{03} & 0 & 0 \\ 0 & 0 & 0 & 0 & H_{03} & 0 \\ 0 & 0 & 0 & 0 & 0 & H_{03}\end{array}\right]$

${ }^{2} \boldsymbol{N}=\left[\begin{array}{cccccccc}H_{02} & 0 & 0 & 0 & 0 & 0 & 0 & 0 \\ 0 & H_{3} & 0 & H_{4} & 0 & 0 & 0 & 0 \\ 0 & 0 & H_{02} & 0 & 0 & 0 & 0 & 0 \\ 0 & 0 & 0 & 0 & H_{02} & 0 & 0 & 0 \\ 0 & 0 & 0 & 0 & 0 & H_{02} & 0 & 0 \\ 0 & 0 & 0 & 0 & 0 & 0 & H_{02} & 0 \\ 0 & 0 & 0 & 0 & 0 & 0 & 0 & H_{02}\end{array}\right]$

CDP model

The yield function of the CDP model can be written as the following form [35]:

$f\left(\bar{\sigma}, \widetilde{\varepsilon}_{p l}\right)=\frac{1}{1-\vartheta}\left(\bar{Q}+\varpi\left(\widetilde{\varepsilon}_{p l}\right)\left\langle\hat{\bar{\sigma}}_{\text {max }}\right\rangle-\kappa\left\langle-\hat{\bar{\sigma}}_{\text {max }}\right\rangle-3 \vartheta \bar{P}\right)-\bar{\sigma}_{c}\left(\widetilde{\varepsilon}_{p l}^{c}\right)$

$\bar{P}$ is the hydrostatic pressure stress; $\bar{Q}$ denotes the Mises equivalent effective stress; $\langle$.$\rangle is the Macauley bracket; \widetilde{\varepsilon}_{p l}^{c}$ and $\widetilde{\varepsilon}_{p l}^{t}$ are equivalent plastic strains in compression and tension. Parameter $\vartheta$ is defined as the follow:

$\vartheta=\frac{1-\left(\sigma_{b 0} / \sigma_{c}\right)}{1-2\left(\sigma_{b 0} / \sigma_{c}\right)}$

where $\sigma_{b 0}$ and $\sigma_{c}$ are the biaxial and uniaxial compressive strength of the concrete, respectively. The function $\varpi\left(\widetilde{\varepsilon}_{p l}\right)$ is given as

$\varpi\left(\widetilde{\varepsilon}_{p l}\right)=\frac{\bar{\sigma}_{c}\left(\widetilde{\varepsilon}_{p l}^{c}\right)}{\bar{\sigma}_{t}\left(\widetilde{\varepsilon}_{p l}^{t}\right)}(1-\vartheta)-(1+\vartheta)$

where $\bar{\sigma}_{c}$ and $\bar{\sigma}_{t}$ are, respectively, the effective compressive and tensile cohesion stresses. The parameter $\kappa$ can be calculated as the below:

$\kappa=\frac{3\left(K_{c}-1\right)}{1-2 K_{c}}$

where $K_{c}$ is the ratio of the tensile to the compressive meridian. 


\section{References}

[1] Jun Hee K, Young-Chan Y. Composite behavior of a novel insulated concrete sandwich wall panel reinforced with GFRP shear grids: effects of insulation types. Materials 2015;8:899-913.

[2] Naito CJ, Hoemann JM, Shull JS, Saucier A, Salim HA, Bewick BT, et al. Precast prestressed Concrete Experiments Performance on Non-load Bearing Sandwich Wall Panels. Air Force Research Laboratory Report, AFRL-RX-TY-TR-2011-0021. Panama City (FL): Tyndall Air Force Base; 2011.

[3] Vidal P, Gallimard L, Polit O. Thermo-mechanical analysis of laminated composite and sandwich beams based on a variables separation. Compos Struct 2016;152:755-66.

[4] Vidal P, Polit O. A refined sinus plate finite element for laminated and sandwich structures under mechanical and thermomechanical loads. Comput Methods Appl Mech Eng 2013;253:396-412.

[5] Lezgy-Nazargah M. Efficient coupled refined finite element for dynamic analysis of sandwich beams containing embedded shear-mode piezoelectric layers. Mech Adv Mater Struct 2016;23(3):337-52.

[6] Lezgy-Nazargah M, Shariyat M, Beheshti-Aval SB. A refined high-order global-local theory for finite element bending and vibration analyses of the laminated composite beams. Acta Mech 2011;217:219-42.

[7] Lezgy-Nazargah M, Beheshti-Aval SB. Coupled refined layerwise theory for dynamic free and forced responses of piezoelectric laminated composite and sandwich beams. Meccanica 2013;48(6):1479-500.

[8] Carrera E, Brischetto S. A survey with numerical assessment of classical and refined theories for the analysis of sandwich plates. ASME Appl Mech Rev 2008;62(1):010803.

[9] Brischetto S, Carrera EL, Demasi L. Improved bending analysis of sandwich plates using a zig-zag function. Compos Struct 2009;89(3):408-15.

[10] D'Ottavio M. A sublaminate generalized unified formulation for the analysis of composite structures. Compos Struct 2016;142:187-99.

[11] Choe J, Huang Q, Yang J, Hu H. An efficient approach to investigate the postbuckling behaviors of sandwich structures. Compos Struct 2018;201:377-88.

[12] Shen H, Sokolinsky VS, Nutt SR. Accurate predictions of bending deflections for soft-core sandwich beams subject to concentrated loads. Compos Struct 2004;64:115-22.

[13] Huang Q, Liu Y, Hu H, Shao Q, Yu K, Giunta G, et al. A fourier-related double scale analysis on the instability phenomena of sandwich plates. Comput Methods Appl Mech Eng 2017;318:270-95.

[14] Saoud KS, Le Grognec P. Post-buckling analysis of elastoplastic sandwich columns by means of an enriched 1D finite element model. Int J Solids Struct 2017;129:90-102.

[15] Le Grognec P, Nguyen QH, Hjiaj M. Exact buckling solution for two-layer Timoshenko beams with interlayer slip. Int J Solids Struct 2012;49:143-50.

[16] Challamel N, Bernard F, Casandjian C. Out-of-plane behavior of partially composite or sandwich beams by exact and finite element methods. Thin-Walled Struct 2010;48(8):561-80.

[17] $\mathrm{Hu} \mathrm{H}$, Belouettar S, Potier-Ferry M, Daya EM. Review and assessment of various theories for modeling sandwich structures. Compos Struct 2008;84:282-92.

[18] Sayyad AS, Ghugal YM. Bending, buckling and free vibration of laminated composite and sandwich beams: a critical review of literature. Compos Struct 2017:171:486-504.

[19] Caliri Jr. MF, Ferreira AJM, Tita V. A review on plate and shell theories for laminated and sandwich structures highlighting the finite element method. Compos Struct 2016;156:63-77.

[20] Carrera E. Theories and finite elements for multilayered, anisotropic, composite plates and shells. Arch Comput Methods Eng 2002;9(2):87-140.

[21] Benayoune A, Samad AAA, Trikha DN, Abang Ali AA, Ashrabov AA. Structural behavior of eccentrically loaded precast sandwich panels. Constr Build Mater 2006;20(9):713-24.

[22] Woltman G, Tomlinson D, Fam A. Investigation of various GFRP shear connectors for insulated precast concrete sandwich wall panels. J Compos Constr 2013;17(5):711-21.

[23] Chen A, Thomas G, Norris P, Hopkins M, Yossef M. Experimental investigation and finite element analysis of flexural behavior of insulated concrete sandwich panels with FRP plate shear connectors. Eng Struct 2015;98:95-108.

[24] Carbonari G, Cavalaro SHP, Cansario MM, Aguado A. Flexural behaviour of lightweight sandwich panels composed by concrete and EPS. Constr Build Mater 2012;35:792-9.

[25] Benayoune A, Samad AAA, Abang Ali AA, Trikha DN. Response of pre-cast reinforced composite sandwich panels to axial loading. Constr Build Mater 2007;21:677-85.

[26] Bai F, Davidson JS. Analysis of partially composite foam insulated concrete sandwich structures. Eng Struct 2015;91:197-209.

[27] Kang J. Composite and non-composite behaviors of foam-insulated concrete sandwich panels. Compos B 2015;68:153-61.

[28] Lezgy-Nazargah M. Assessment of refined high-order global-local theory for progressive failure analysis of laminated composite beams. Acta Mech 2017;228(5):1923-40.

[29] Lezgy-Nazargah M. An efficient materially nonlinear finite element model for reinforced concrete beams based on layered global-local kinematics. Acta Mech 2018;229(3):1429-49.

[30] Vidal P, Polit O. A family of sinus finite elements for the analysis of rectangular laminated beams. Compos Struct 2008;84:56-72.

[31] Lezgy-Nazargah M, Vidal P, Polit O. NURBS-based isogeometric analysis of laminated composite beams using refined sinus model. Eur J Mech A Solids 2015;53:34-47.

[32] Beheshti-Aval SB, Lezgy-Nazargah M, Vidal P, Polit O. A refined sinus finite element model for the analysis of piezoelectric-laminated beams. J Intell Mater Syst Struct 2011;22(3):203-19.

[33] Naito CJ, Hoemann JM, Bewick BT, Hammons MI. Evaluation of shear tie connectors for use in industrial concrete sandwich panels. Panama City (FL): Tyndall Air Force Base; 2009. Air Force Research Laboratory Report, AFRL-RX-TY-TR-20094600.

[34] Newberry CM, Davidson JS, Hoemann JM, Bewick BT. Simulation of prestressed concrete sandwich panels subjected to blast loads. Air Force Research Laboratory, AFRL-RX-TY-TP-2010-0014, Preprint, Feb. 2010.

[35] Lezgy-Nazargah M, Dezhangah M, Sepehrinia S. The effects of different FRP/concrete bond-slip laws on the 3D FE modeling of retrofitted RC beams - A sensitivity analysis. Steel Compos Struct 2018;26(3):347-60. 